\title{
Doadores, partidos e estratégias para 0 financiamento de campanhas eleitorais no Brasil: uma análise sobre o reduzido número de doadores e os elevados valores doados para os candidatos a presidente em 2014
}

Emerson Urizzi Cervi ${ }^{1}$

\begin{abstract}
Resumo
0 trabalho insere-se na linha de pesquisas sobre financiamento de campanhas para discutir a importância tanto da origem, quanto da forma de doações a candidaturas nacionais no Brasil, em 2014. 0 objetivo é descrever como são feitas as doações e de que forma são declaradas as doações às campanhas nacionais. Para melhor compreensão das decisões específicas, são comparadas as declarações de receitas do PT e PSDB com os demais partidos na disputa de 2014. Entre os principais achados estão o fato de as doações diretas a candidatos representaram apenas $1 / 3$ do total de $\mathrm{R} \$ 1,8$ bi declarado nas campanhas nacionais e que apesar de ser altamente aberto e democrático, na prática o sistema de financiamento das campanhas é "fechado" a um grupo reduzido de grandes empresas que aportaram somas consideráveis nas campanhas presidenciais. Menos de 0,01\% dos doadores foram responsáveis por mais de $20 \%$ dos recursos declarados pelas campanhas nacionais.
\end{abstract}

Palavras-chave: Eleições, financiamento, presidente, Brasil, 2014.

\section{Introdução}

Os recursos financeiros têm se tornado um dos principais "combustíveis" para as máquinas partidárias em democracias de massa contemporâneas. Em especial nos períodos eleitorais. Desde o mais recente período de redemocratização no Brasil, os partidos políticos têm se adaptado às novas condições, substituindo posições marcadas por discursos eleitorais ideologicamente centrados por propostas de curto prazo que atendam as expectativas dos financiadores da

\footnotetext{
1 Doutor em Ciência Política. Professor permanente do Programa de Pós-Graduação em Ciência Política e do Programa de Pós-graduação em Comunicação da Universidade Federal do Paraná (UFPR). E-mail: ecervi7@gmail.com.
} 
democracia. Ter estrutura e recursos para vencer eleições, o maior número possível de cadeiras nos legislativos, e, principalmente, os postos centrais nos Executivos é o que garante a sobrevivência dos partidos nos sistemas políticos vigentes no início do século XXI (Sáez, 2013). No Brasil não é diferente. Desde a lei 9.504/97, que estabeleceu novas regras para o funcionamento e financiamento dos partidos políticos, a elite política tem dado crescente importância ao financiamento de suas eleições. Esses novos padrões explicam relações recentes entre partidos, administrações públicas e sociedade. Desde 1992, após o "escândalo-Collor", quando foi comprovada a associação entre Caixa 2 de campanha para presidente do Brasil e direcionamento de recursos públicos para fornecedores privados, a legislação brasileira vem se adaptando para tornar mais universais e transparentes as relações entre dinheiro, política e voto no País ${ }^{2}$. Uma maior transparência do sistema de financiamento político gera condições para fiscalização, enquanto a permissividade das relações entre partidos e financiadores pode resultar em distorções que levam os partidos a preferirem determinados financiadores a outros.

0 objetivo do artigo é discutir as relações entre financiadores de campanhas e partidos políticos no Brasil a partir de um estudo de caso: doações diretas e indiretas aos candidatos às eleições presidenciais de 2014. Seguindo uma tradição já consolidada na literatura da ciência política brasileira sobre financiamento político, pretende-se demonstrar como diferentes tipos de doadores ajudam a financiar as campanhas nacionais, em especial às de presidente da república. Não é nosso objetivo traçar relações de causalidade entre dinheiro e voto, mas de apontar determinados tipos de associações entre quem doa e as formas como os recursos doados entram nas campanhas. Pretendemos descrever as diferentes formas de doações às campanhas nacionais, dado que o recebimento direto ou indireto pelo candidato a presidente pode indicar diferenças importantes nas estratégias de arrecadação. Dado esse objetivo, pretendemos ir além das doações aos candidatos. Incorporamos as entradas de recursos via comitê financeiro e diretório nacional do partido. Como os recursos doados ao partido podem ser direcionados a campanhas regionais, não trataremos como campanhas presidenciais, mas sim como recursos destinados a campanhas nacionais. Um partido pode destinar tanto para a campanha presidencial, quando para as disputas regionais as doações que recebe

\footnotetext{
20 relatório final da Comissão Mista de Inquérito sobre o "escândalo-Collor", com recomendações paramudanças na legislação de financiamento de campanha, pode ser acessado em:

http://www.senado.gov.br/atividade/materia/getPDF.asp?t=56330\&tp=1
} 
por diretório nacional. No entanto, consideramos que ao doar ao diretório nacional o doador indica a intenção de não se vincular a uma campanha regional, mas sim à disputa nacional. Embora exista o risco de alguma imprecisão a respeito de doações a candidatos a presidente, a opção metodológica adotada aqui permite identificar os montantes de recursos destinados aos comitês financeiros e aos diretórios nacionais, que não aparecem como doações para as campanhas presidenciais ainda que nem todas as doações sejam destinadas diretamente aos candidatos a presidente, como se verá adiante. Dada a grande concentração de recursos em poucos doadores, já descrito pela literatura, a hipótese testada neste artigo é que os doadores e partidos adotam estratégias distintas de financiamento de campanha. As diferentes estratégias podem ser explicadas pela posição do partido na disputa. Partimos do fato já demonstrado pela literatura da área de que o incumbent (candidato à reeleição) tende a ter um volume maior de receitas de doações diretas ao candidato ou à campanha (SPECK, 2005; SAMUELS, 2002). Já os partidos de oposição recebem mais doações via partido ou comitê financeiro, sem a possibilidade de vínculo direto ao candidato. Embora o artigo trate de todas as campanhas nacionais de 2014, para testar as hipóteses, focaremos atenção nas doações ao partido que disputou a reeleição, Partido dos Trabalhadores (PT), e no seu principal adversário, o partido que foi ao segundo turno, Partido da Social Democracia Brasileira (PSDB).

A ciência política brasileira tem produzido estudos sobre financiamento de campanhas a partir de dois eixos principais. Em um deles estão os trabalhos que estudam os interesses dos doadores para financiar o sistema político (FIGUEIREDO, 2009; SANTOS, 2011; SPECK, 2005; SPECK \& MANCUSO, 2011). Esse tipo de análise é o mais difundido inclusive na literatura internacional comparada da área (MANN, 1999; ALMEIDA, 2001; SAMUELS, 2001a; SAMUELS, 2001b; PINTO-DUSCHINSKY, 2002; FISCHER \& EISENSTADT, 2004; LIMA, 2004; ZOVATTO, 2005; BIENZEN \& KOPECKY, 2007; BOUDOKAN, 2008). Trata-se de analisar quem faz doações, para quem doa e porque doa dinheiro para partidos ou candidatos. Nesse caso, o dinheiro é a variável a ser explicada. No outro eixo estão as pesquisas que tratam recursos financeiros como variável explicativa. Aqui, o objetivo é entender quais os efeitos gerados pela distribuição de recursos no sistema eleitoral (ROSEN, 1981; JONES, 1981; TAAGEPERA E SHUGART, 1989; HOPKIN, 2004; HEILER, 2011; PEIXOTO, 2005; BRAGA \& BOUDOUKAN, 2009; CERVI, 2010; SILVEIRA \& MELLO, 2011). Busca-se identificar quanto do sucesso nas eleições pode ser explicado pela maior ou menor igualdade na distribuição dos recursos financeiros. Do ponto de vista comparativo, esses efeitos podem ser 
Doadores, partidos e estratégias para o financiamento de campanhas eleitorais no Brasil: uma análise sobre o reduzido número de doadores e os elevados valores doados para os candidatos a presidente em 2014 - Emerson Urizzi Cervi

medidos em relação aos partidos, às suas posições no espectro ideológico, aos cargos eletivos ou até mesmo às diferentes abrangências (local, estadual ou nacional) de disputa (KATZ \& MAIR, 1995; SAMUELS, 2001c; SCARROW, 2004; RUBIO, 2005).

0 ponto comum entre os dois eixos descritos acima é que ambos consideram partidos e doadores como agentes racionais, que buscam agir estrategicamente em campanhas eleitorais. Quem doa quer favorecer seu partido, candidato ou até mesmo favorecer a si mesmo diante da impossibilidade de controlar, pelo menos em parte, os resultados ${ }^{3}$. Os partidos que apresentam candidatos e buscam recursos para financiar suas campanhas são agentes que agem estrategicamente ao maximizar os ganhos com atração de maiores doadores para suas campanhas. As estratégias adotadas pelos agentes políticos dependem das "regras do jogo" e da organização institucional que faz a ligação entre as ações de quem recebe os recursos e os interesses de quem faz doações de recursos financeiros. 0 objeto de estudo desenvolvido aqui é como se deu essa ligação nas campanhas nacionais de 2014, a partir de que formas de doação, tipos de doadores, volumes de recursos doados por doador e para quais partidos/candidatos foram destinadas doações. Partindo do fato de que doadores e partidos são agentes racionais, os mesmos agem em função das possibilidades e limites estabelecidos pela legislação eleitoral. A consequência para a literatura da área é que muitas vezes os estudos de casos de uma eleição anterior podem não servir mais como ponto de partida para a descrição das ações em disputas seguintes, após mudanças nas "regras do jogo". Um exemplo disso é a possibilidade de doações a partidos e não apenas a candidatos.

O tema do financiamento e das relações entre doadores e partidos políticos não é recente no Brasil. Desde 1940, quando surge a atual estrutura da justiça eleitoral no Brasil, tem chamado atenção dos pesquisadores 4 . Nas primeiras duas décadas, até meados dos anos 1960, o sistema era muito fechado, permitindo doações apenas dos próprios candidatos ou de filiados a partidos políticos. A partir de 1965, a lei 4.740 cria o Fundo Partidário para Custeio das Atividades dos Partidos Políticos e amplia o escopo de doadores, passando a ser permitida a doação de recursos para campanhas eleitorais por

\footnotetext{
3 Isso explica o fato de um doador fazer doações a diferentes candidatos ou partidos. 4 Antes dos estudos específicos sobre financiamento de campanha, cientistas políticos se preocupavam em explicar, também a partir dos princípios de decisão racional, as formas de organização partidária e para disputas eleitorais como abordagem principal sobre as relações entre partidos e sociedade brasileira em períodos eleitorais (Marenco dos Santos, 2000; Fleischer, 2002; Rodrigues, 2006; Guarnieri, 2014).
} 
qualquer eleitor. Na sequência, em 1971 as empresas passam a ser expressamente proibidas de fazer doações a partidos ou campanhas. Só em 1993, com a lei 8.713, é que as empresas são autorizadas a fazer doações a partidos políticos. Como consequência do "escândalo-Collor", que teve sua origem nas doações ilegais de empresas, via Caixa-2, às campanhas eleitorais. É justamente em 1993 que surgem os comitês financeiros de campanha, responsáveis pela organização e prestação de contas dos candidatos. A partir de então acontecem apenas mudanças pontuais no sistema de financiamento eleitoral, tal como a de 2009, que regulamenta as doações pela internet.

Um dos principais objetos de atenção das pesquisas em financiamento político é identificar quem participa dos processos doando ou recebendo doações - e como operam empiricamente o sistema a partir dos limites estabelecidos pelas regras e instituições. Assim, pretende-se basicamente descrever o comportamento dos atores políticos e por isso predominam estudos empírico-descritivos a partir de um ou alguns casos selecionados. 0 volume de pesquisas descritivas sobre dinheiro e política tem crescido nos últimos anos no Brasil como consequência das políticas de transparência. As prestações de contas dos candidatos, disponibilizadas ao público pelo Tribunal Superior Eleitoral (TSE), tem contribuído para o desenvolvimento desse campo de estudos. Este trabalho utiliza os bancos de dados das prestações de contas finais dos partidos e candidatos disponibilizados ao público em $28 / 11 / 2014^{5}$ e do qual constam mais de 8 mil operações de doações às campanhas nacionais, para presidente, entre julho e outubro de 2014. Nossa questão de pesquisa é: como participaram do financiamento das campanhas nacionais de 2014 os diferentes tipos de doadores e quais as formas predominantes de doações?

Para buscar respostas à questão acima, são utilizadas duas variáveis que categorizam os doadores e ajudam a entender os diferentes tipo de participação de doadores e suas relações com os partidos políticos. A primeira é o tipo de doador, que em função da maior abertura do sistema, hoje são oito os possíveis tipos de doadores a uma campanha eleitoral. Vai desde o próprio candidato, passado por pessoas físicas/doações pela internet, pessoas jurídicas, o próprio partido político, outros partidos e candidatos, receitas de eventos, da comercialização de bens e até mesmo os rendimentos financeiros são contabilizados como receita de campanha. 0 tipo de doador indica a

5 Pequenas alterações podem ocorrer em bancos de dados atualizados posteriormente a essa data devido ao julgamento de contas, entrada ou retirada de operações de doações. No entanto, essas mudanças não são suficientemente fortes para alterar os resultados gerais das análises. 
Doadores, partidos e estratégias para o financiamento de campanhas eleitorais no Brasil: uma análise sobre o reduzido número de doadores e os elevados valores doados para os candidatos a presidente em 2014 - Emerson Urizzi Cervi

forma como as campanhas recebem os recursos. Estudos sobre eleições indicam o crescimento dos montantes de recursos doados por pessoas jurídicas às campanhas. Em 2014, para as campanhas nacionais, elas foram responsáveis por $R \$ 3,00$ em cada $R \$ 4,00$ das doações declaradas pelos diretórios nacionais, comitês financeiros e candidatos. Um fenômeno crescente nas eleições brasileiras, tanto para cargos no Executivo quanto no Legislativo, tem sido o das doações indiretas, não ao candidato, mas ao partido ou comitê financeiro, que se responsabiliza por repassar os recursos às campanhas. Para permitir a diferenciação entre os tipos de entrada de recursos na campanha, o TSE aceita trêstipos de entradas nas prestações de contas: diretamente ao candidato, via diretório do partido político ou via comitê financeiro da campanha. Em 2014, nas disputas nacionais, apenas $1 / 3$ das doações foram diretamente a candidatos a presidente, mais de $50 \%$ foram dirigidas aos diretórios nacionais dos partidos políticos e o restante aos comitês financeiros. Esses números iniciais indicam a existência de uma ação estratégica dos doadores, que nem sempre se vinculam diretamente aos candidatos, principalmente quando se trata de grandes doadores, que fazem doações a vários candidatos. Além disso, a informação indica também que as análises que consideram apenas os recursos doados diretamente a candidatos são incapazes de identificar a maior parte do dinheiro de campanha e podem gerar grandes distorções nas análises entre doador e campanha.

Para tentar incluir todos os recursos destinados às campanhas presidenciais, excluindo as possíveis doações para candidatos a outros cargos, o artigo abordará as doações declaradas por três tipos de entradas: i) Diretório Nacional do Partido, que incluem os diretórios nacionais de todos os 32 partidos que disputaram as eleições de 2014. Apenas 11 deles apresentaram candidatos à presidência, mas a maioria fez doações a partidos com candidatos por fazerem parte de coligações com candidatos e receberam doações de diferentes tipos de fontes. Não é possível afirmar que a totalidade de doações a diretórios nacionais foi destinada às campanhas presidenciais. Parte deles foi dirigida a candidatos do partido às disputas estaduais ou até mesmo a candidatos de outros partidos, nas coligações. Por esse motivo é que optamos em tratar de campanhas nacionais - dado que as doações foram feitas aos diretórios nacionais dos partidos - e não exclusivamente às campanhas presidenciais. Por considerarmos apenas os recursos destinados às estruturas partidárias nacionais ou candidatos presidenciais, foram consideradas apenas as doações aos diretórios nacionais, ficando excluídos os diretórios estaduais; ii) Comitê Financeiro Nacional para Presidente da República. É o comitê aberto pelos partidos para administrar recursos de candidaturas a presidente. Partidos sem 
candidato, mas que optaram por abrir comitê nacional para administrar transferências de recursos a outras siglas, também podem ter comitê para Presidente da República. Nesse caso, a totalidade de recursos recebidos pelo comitê será transferida à campanha de um candidato à presidência por outro partido - normalmente coligado. Desconsideramos os recursos destinados a todos os demais comitês financeiros, inclusive o comitê único de campanha, pois todos os demais comitês recebem doações destinadas a campanhas estaduais, de governador, senador, deputado federal ou estadual. Com isso, se no primeiro tipo de entrada, pelos diretórios nacionais, abrimos a possibilidade de considerar recursos não destinados às campanhas presidenciais, o recorte feito ao tipo de comitê financeiro, restringe a possibilidade de considerar doações feitas a candidaturas à presidência via outro comitê que não o exclusivamente para Presidente da República. $\mathrm{O}$ objetivo é tentar neutralizar possíveis distorções geradas pelo recorte. De qualquer maneira, a consideração de doações a comitê financeiro e a diretório nacional nos impede de falar sobre doações estritamente a campanhas para presidente, como explicado acima. Pode-se dizer que estamos tratando de doações para campanhas nacionais, cujo cargo diretamente em disputa é o de Presidente da República. Por fim, iii) Doações a Candidatos a Presidente. Aqui foram considerados apenas o total dos valores declarados como recebidos diretamente pelos 11 candidatos à presidência em 2014. A somatória desses três tipos de entradas de recursos, segundo as prestações de contas, ultrapassa $\mathrm{R} \$ 1,8$ bilhão para a campanha nacional dos partidos.

A partir daqui o texto está dividido em três partes. Na primeira são discutidas as regras e forma como se organizaram as doações de recursos para a campanha nacional de 2014. Em seguida são apresentados os dados eas análises. Após a sumarização descritiva dos dados agregados usa-se o teste de Análise de Componentes Principais para identificar possíveis associações entre valores, tipo de doador e tipo de entrada nas campanhas. Todas as análises são divididas em dois momentos. No primeiro são tratados os totais das doações a todas as campanhas nacionais. Em seguida há um detalhamento para os dois principais partidos da disputa nacional de 2014: PT e PSDB. A análise encerra-se com uma descrição da participação dos cinco maiores doadores das campanhas nacionais de 2014. Embora eles representem apenas $0,01 \%$ do número de doadores, a participação deles no volume de recursos doados ultrapassou $20 \%$ do total, demonstrando ser uma das maiores concentrações de recursos por fonte doadora das democracias modernas. 0 tratamento dado aos principais doadores permite identificar diferentes estratégias deles quanto a doar diretamente ao candidato, ao partido ou ao comitê, assim como é 
Doadores, partidos e estratégias para o financiamento de campanhas eleitorais no Brasil: uma análise sobre o reduzido número de doadores e os elevados valores doados para os candidatos a presidente em 2014 - Emerson Urizzi Cervi

mostrado quanto cada grande doador transfere para o PT, para o PSDB e para os demais partidos/candidatos. 0 tópico final é o das conclusões possíveis a partir deste estudo de caso.

\section{0 financiamento de campanhas no Brasil em 2014}

A resolução TSE 23.406/20146 normatizou a arrecadação de recursos e gastos de campanha para as eleições de 2014 mantendo a distinção que já existia entre a forma de arrecadação e a origem dos recursos. A forma de arrecadação depende da maneira como os partidos organizam-se para prestar contas das finanças de campanha e podem ser de três tipos: i) pelo próprio candidato; ii) pelo diretório do partido político, ou iii) por comitê financeiro constituído especificamente para gerir os recursos de campanha. Já a origem dos recursos é dividida em oito categorias: i) recursos do próprio candidato, ii) doações de pessoas físicas (nesse caso há uma diferenciação na prestação de contas para as doações de pessoas físicas feitas pela internet), iii) doações de pessoas jurídicas, iv) doações de partidos/comitê ou outros candidatos, v) recursos do próprio partido político $^{7}$, vi) recursos do fundo partidário, vii) receitas da comercialização de bens ou serviços, e viii) receitas de promoção de eventos durante a campanha. A não identificação do doador ou falta de CPF ou CNPJ na prestação de contas são suficientes para caracterizar o recurso como sendo de "origem não identificada". A legislação determina que os recursos que não têm identificação de origem não podem ser usados na campanha e devem ser transferidos ao Tesouro Nacional até o final do prazo estabelecido para prestação de contas à justiça eleitoral. No caso das campanhas nacionais de 2014 houve apenas uma doação de $\mathrm{R} \$ 200,00$ à campanha do PSDB que se enquadrou como "origem não identificada".

\footnotetext{
6 Disponível em:

http://www.tse.jus.br/eleicoes/eleicoes-2014/normas-e-

documentacoes/resolucao-no-23.406. Acesso em 05/02/2015.

7 No caso de transferências do próprio partido, a regulamentação determina que sejam identificadas a origem dos recursos. Assim, é possível diferenciar o que é financiamento partidário de origem do Fundo de Assistência Financeira aos Partidos Políticos (Fundo Partidário) das doações feitas por terceiros (pessoas físicas ou jurídicas) aos partidos e que depois são direcionadas às campanhas. Até 2010 não era possível identificar a origem dos recursos via partido político, o que gerou a ocultação de possíveis doadores que não podiam ser relacionados a partidos ou candidatos. A partir de 2014, com a exigência de identificação da origem, mesmo as doações via partido político para candidatos que não são provenientes do Fundo Partidário podem ser identificadas.
} 
Para as candidaturas a presidente a resolução estabelece a obrigatoriedade de três formas de arrecadação: i) pelo próprio candidato, que é obrigado a abrir conta corrente pessoal exclusiva para depósitos e gastos de campanha; ii) o diretório nacional do partido político, que também pode receber doações e realizar despesas de campanha ou ainda iii) comitê financeiro nacional para presidente da república. Esse comitê é criado exclusivamente para fazer o controle das receitas e despesas dos candidatos. Todo partido com candidato a presidente precisa constituir um comitê financeiro, que não pode ser comitê de coligação, mas sim de partido ${ }^{8}$. Com isso, a resolução do TSE define três formas de entradas de recursos nas campanhas eleitorais para presidente e não apenas pelos próprios candidatos. Essa possibilidade faz com que os doadores adotem estratégias distintas para financiamento de candidaturas, em especial as pessoas jurídicas, que não raras vezes fazem doações para vários partidos ou candidatos. Mesmo partidos que não têm candidatos à presidência podem receber doações através de seus diretórios nacionais para investir em candidaturas próprias nas Unidades da Federação ou para fazer transferências a partido com candidato presidencial, normalmente integrante da mesma coligação nacional. Como será apresentado a seguir, no que diz respeito ao volume de recursos, a forma de entrada preferida dos doadores para as campanhas nacionais de 2014 foi para partidos políticos, que representaram 52,5\% do total de valores doados. Já em relação ao número de operações, as doações aos comitês financeiros representaram 39,8\% do total. Doações diretamente aos candidatos a presidente ficaram restritas a pouco mais de $1 / 4$ do total das operações e pouco mais de $1 / 3$ do total de valores. Por esse motivo optamos em analisar o conjunto de doações a todos os tipos de entradas para as campanhas, visto que se selecionássemos apenas as doações diretamente aos candidatos haveria grandes distorções ao se desconsiderar cerca de $2 / 3$ de todos os recursos arrecadados pelas campanhas nacionais dos partidos.

Em relação aos tipos de origem, a resolução 23.406/14 reforça o que é definido como limites para cada tipo de doador na lei 9.096/95. A autodoação ou uso de recursos do próprio candidato apresenta duas limitações. A primeira é a limitação definida pelo partido do candidato, que estabelece qual será o valor máximo que cada candidato pode usar

80 cargo de presidente é o único que tem a obrigatoriedade de possuir comitê financeiro. Para os candidatos aos demais cargos o partido pode optar por receber recursos pelo candidato ou pelo próprio partido. No entanto, se optar por comitê financeiro, existem as opções de comitês para cada um dos cargos (governador, senador, deputado federal, deputado estadual e deputado distrital) ou a opção de comitê financeiro único. 
de seu próprio patrimônio na campanha eleitoral ${ }^{9}$. 0 segundo limite para as autodoações estabelecido pela resolução é o de que os recursos próprios não poderão ultrapassar $50 \%$ do patrimônio pessoal informado à Receita Federal no ano anterior à campanha. Isso significa que cada candidato pode gastar no máximo metade do seu patrimônio individual na campanha. Embora esse limite mantenha as distorções já existentes na sociedade brasileira, favorecendo concorrentes com mais patrimônio, nas campanhas presidenciais o percentual de autodoações foi insignificante, ficando restrito a apenas três candidatos nanicos ${ }^{10}$.

As doações de pessoas físicas e pessoas jurídicas estavam limitadas em termos proporcionais à renda ou faturamento no ano anterior, respectivamente. As pessoas físicas podem doar até $10 \%$ da renda declarada no ano anterior à Receita Federal, enquanto as pessoas jurídicas podem doar até $2 \%$ do faturamento declarado no ano anterior. 0 número de doações e número de candidatos que podem receber as doações não é limitado. Por exemplo, uma única empresa, a JBS S/A, fez 102 operações de doações para vários partidos, comitês financeiros e candidatos em 2014, considerando apenas as campanhas nacionais. Como a campanha teve quatro meses, ela realizou mais de uma doação por dia útil durante a disputa eleitoral para presidência da república. A inexistência de limites nominais para as doações mantém as distorções geradas pelas desigualdades de condições econômicas presentes na sociedade brasileira. Os mais ricos ou as empresas com maior faturamento podem fazer doações mais vultosas aos candidatos do que os mais pobres e as empresas menores ${ }^{11}$.

Um candidato pode, também, receber doações de seu próprio partido. Esses recursos são identificados como sendo originários do Fundo Partidário ou então de pessoas físicas ou jurídicas que fizeram doação ao partido e não ao candidato. Por esse motivo a legislação determina que sejam identificadas as origens dos recursos partidários, diferenciando as doações indiretas a campanhas dos recursos do fundo partidário. Outros partidos, candidatos ou comitês financeiros podem

\footnotetext{
${ }^{9}$ Embora a justiça eleitoral possa estabelecer esses limites, até a eleição de 2014 a prática tem sido deixar que os partidos o façam. Normalmente os partidos estabelecem limites de autodoações muito altos, favorecendo candidatos que possuem mais recursos.

100 mesmo não acontece em disputas para cargos legislativos, onde o percentual de autodoações para as campanhas torna-se bastante significativo no montante geral de recursos.

11 Outra particularidade das doações de pessoas físicas e jurídicas é que elas podem ser em dinheiro ou em valores estimados. Isso significa que uma parte dos recursos declarados entra nas campanhas na forma de prestação de serviços ou fornecimento de materiais, por exemplo, e não em dinheiro.
} 
fazer doações a candidatos, conforme prevê a lei. Esse tipo de operação é bastante comum entre transferências de recursos da esfera nacional para a estadual ou entre siglas que fazem parte da mesma coligação.Os candidatos podem ter como fonte de recursos, ainda, valores auferidos da comercialização de bens durante a campanha - como botons, bandeiras etc. -, da realização de eventos - tais como jantares de apoio ao candidato - ou como resultado de aplicações financeiras dos recursos de campanha. Invariavelmente o peso dos recursos provenientes desse tipo de receita é muito baixo no volume arrecadado pelas campanhas nacionais.

Se considerarmos os oito tipos de doadores e os três tipos de entradas (candidatos, comitês financeiros e partidos) as campanhas nacionais de 2014 tiveram arrecadação declarada de $\mathrm{R} \$ 1,8$ bilhão em 2014. A maior parte dos valores teve origem em doações de pessoas jurídicas, que representaram $71,4 \%$ da arrecadação; outros candidatos/comitê, $14,7 \%$; e, partidos políticos, $12,7 \%$ do total. Ou seja, pessoas jurídicas e os partidos representaram 98,8\% do total de recursos arrecadados pelas campanhas nacionais. As pessoas físicas representaram apenas $1,2 \%$ do total doado às candidaturas.

A desproporção gerada pela falta de limites nominais nas regras de doações fica evidente quando comparamos os percentuais de volumes doados com os percentuais de número de operações de doação. 0 tipo de doador que realizou o maior número de operações foi o doador pela internet, com 55,3\% do total de operações de doação, embora represente menos de $0,01 \%$ do volume de doações. As pessoas jurídicas realizaram apenas $26 \%$ do total de operações, mas, como os limites são percentuais e não nominais, com poucas doações elas conseguem gerar um volume maior de receitas para as candidaturas. 0 modelo vigente favorece a relação entre partidos e pessoas jurídicas, tornando pouco "rentável" o "investimento" em contato permanente e busca de recursos de eleitores comuns para o financiamento das campanhas eleitorais no Brasil, em especial as que são de abrangência nacional.

No próximo tópico descrevem-se as doações às campanhas nacionais em 2014 por tipo de doador e tipo de entrada de recursos. As descrições são feitas em duas partes. Na primeira estão sumarizados os resultados de toda a campanha e na sequência são comparados os dados dos dois principais partidos da disputa (PT e PSDB) com os demais. Para identificar possíveis associações entre tipo de doador, tipo de entrada e valor da doação será realizado o teste de Análise de Componentes Principais. Por fim, são apresentados os dados de doações dos cinco maiores doadores das campanhas nacionais de 2014, 
Doadores, partidos e estratégias para o financiamento de campanhas eleitorais no Brasil: uma análise sobre o reduzido número de doadores e os elevados valores doados para os candidatos a presidente em 2014 - Emerson Urizzi Cervi

o que permitirá identificar estratégias específicas de distribuição de recursos entre os principais partidos e os diferentes tipos de entradas nas candidaturas.

\section{Apresentação dos dados e análises}

Se considerarmos as doações aos candidatos à presidência, diretórios partidários nacionais e comitês financeiros de campanha de todos os partidos é possível perceber grandes diferenças entre o número de operações e os valores doados por tipo de doador. Do total de operações realizadas, 8.31412 , mais da metade, 55,3\%, foi de doações pela internet. Em segundo lugar está o número de operações realizadas por pessoas jurídicas, $26 \%$ do total. Depois, em proporção de participação muito reduzida, seguem as doações de partidos políticos, 7,9\%; doações de pessoas físicas, 6,3\% e doações de outros candidatos ou comitês de campanha, 4,1\%. Em número bastante baixo de operações, seguem as aplicações financeiras, operações de recursos próprios e origens não identificadas, todos abaixo de $1 \%$ do total.

Em relação aos valores doados há significativas diferenças. Em primeiro lugar uma concentração de recursos doados por pessoas jurídicas. Do total de $\mathrm{R} \$ 1,8$ bi para as campanhas nacionais, as pessoas jurídicas foram responsáveis por $\mathrm{R} \$ 1,3$ bi. Já as doações por internet somaram apenas $\mathrm{R} \$ 677,7$ mil, com participação de menos de $0,1 \%$ do total em valores. 0 segundo principal tipo de doador para as candidaturas presidenciais, em termos de valores, foi "outros candidatos/comitês", com 14,7\%, seguido de partido político, com $12,7 \%$. Se levarmos em conta que os recursos do fundo partidário representam uma pequena parte do total dos partidos e que a maior parte é doação de pessoas jurídicas aos partidos, a participação real desse tipo de doador nas finanças de campanhas nacionais pode ultrapassar os $80 \%$ do total. As doações de pessoas físicas totalizaram $\mathrm{R} \$ 21,7$ milhões, representando apenas 1,2\% do total, conforme mostra a Tabela 1.

12 Em 2014, para as campanhas nacionais, as 8.314 operações de doações foram realizadas por 5.903 doadores diferentes (identificados por CPF, quando pessoa física, ou CNPJ, quando pessoa jurídica ou partido político). Isso significa que uma parte dos doadores fez duas ou mais doações. Em média, os 5.903 doadores fizeram 1,4 operações para as campanhas nacionais. 0 maior número de doações ficou por conta da JBS, que realizou 102 operações de doações às campanhas nacionais de diferentes partidos/candidatos. No geral, os doadores comuns fazem apenas uma operação durante toda a campanha. 
Tabela 1 - Operações de doação a campanhas nacionais por tipo de doador (2014)

\begin{tabular}{l|r|r|r|r|r}
\multicolumn{1}{c|}{ Tipo doador } & \multicolumn{1}{c|}{ N } & \multicolumn{1}{c|}{ V } & \multicolumn{1}{c|}{ Valor } & \multicolumn{1}{c|}{ \% } & \multicolumn{1}{c}{ Valor/N } \\
\hline Pessoas jurídicas & 2.164 & 26,0 & $1.302 .876 .922,3$ & 71,4 & $602.068,8$ \\
\hline Outros candidatos/comitês & 343 & 4,1 & $267.382 .908,0$ & 14,7 & $779.542,0$ \\
\hline Partido político & 656 & 7,9 & $232.278 .398,8$ & 12,7 & $354.082,9$ \\
\hline Pessoas físicas & 522 & 6,4 & $21.716 .197,0$ & 1,2 & $41.601,9$ \\
\hline Doações pela Internet & 4.600 & 55,3 & $677.784,2$ & 0,0 & 147,3 \\
\hline Aplicações financeiras & 25 & 0,3 & $124.688,8$ & 0,0 & $4.987,6$ \\
\hline Recursos próprios & 3 & 0,0 & $8.300,0$ & 0,0 & $2.766,7$ \\
\hline Origens não identificadas & 1 & 0,0 & 200,0 & 0,0 & 200,0 \\
\hline Total & 8.314 & 100,0 & $1.825 .065 .399,1$ & 100,0 & $219.517,1$ \\
\hline
\end{tabular}

Fonte: autor, a partir de dados do TSE.

Outra forma de analisar o impacto dos diferentes tipos de doadores às campanhas é pelo valor médio de doação, dividindo-se o total pelo número de operações para cada tipo de doador. Desconsiderando as variações, que são altas, o resultado será equivalente ao "ticket médio" de doação por tipo. Quanto maior essa média, mais importante é o doador individual para a campanha. De acordo com a tabela acima, a maior média, $\mathrm{R} \$ 779,5$ mil, foi em doações de "outros candidatos/comitês", seguido da média de R\$ 602 mil para as doações de pessoas jurídicas. Já as doações de partidos políticos ficaram com a média de $\mathrm{R} \$ 354$ mil. Depois há uma queda significativa nos valores médios, com $\mathrm{R} \$ 41,6$ mil de média por operação de pessoas físicas e $\mathrm{R} \$ 4,9$ mil para aplicações financeiras. A média de valor por doação pela internet foi a mais baixa, com $\mathrm{R} \$ 147,3$ de média. Esses valores mostram como as doações pela internet foram a única modalidade capaz de inserir o eleitor comum no rol de doadores de campanha, pois mesmo para as pessoas físicas a média de $\mathrm{R} \$ 41,6$ mil por doação é inviável para a maioria dos eleitores brasileiros.

Feitas as descrições para todos os partidos, a seguir discutiremos os padrões de doação por tipo de doador para as duas principais candidaturas na disputa nacional: PT e PSDB. A candidatura do PT teve um número maior de doações, 1.918, do que a do PSDB, com 677 operações. No entanto, os totais em reais doados aos dois partidos ficaram muito próximos entre si, com $\mathrm{R} \$ 544,7$ mi para o PT e $\mathrm{R} \$ 528,6$ mi para o PSDB, uma diferença percentual de apenas $3 \%$ entre os valores arrecadados. Além disso, embora o número de operações somadas ao PT e PSDB fique abaixo de $30 \%$ do total de doações feitas às campanhas nacionais, em termos de valores, os dois partidos arrecadaram quase $60 \%$ de tudo o que foi doado aos 11 candidatos à presidência e aos 32 diretórios nacionais partidários em 2014, 
Doadores, partidos e estratégias para o financiamento de campanhas eleitorais no Brasil: uma análise sobre o reduzido número de doadores e os elevados valores doados para os candidatos a presidente em 2014 - Emerson Urizzi Cervi

indicando uma concentração de recursos nos dois partidos que foram para o segundo turno.

No PT o maior número de doações foi pela internet, $62,2 \%$ do total, seguido das doações de pessoas jurídicas, 30,7\%. Os outros tipos apresentaram participações pouco relevantes. Já em termos de valores, as doações de pessoas jurídicas representaram mais de 90\% do total de recursos arrecadados pela campanha nacional. Em seguida vieram os valores de partidos políticos, com 7\%. Outros candidatos/comitês ficaram em $1,6 \%$, enquanto doações de pessoas físicas $(0,4 \%)$ e pela internet $(0,1 \%)$ foram insignificantes. No geral, a média por operação de doação à campanha nacional do PT foi de R\$284 mil. Os valores médios por tipo de doador ao PT indicam grandes diferenças entre pessoas jurídicas, com média de $\mathrm{R} \$ 841,8$ mil, e partido político, com $\mathrm{R} \$$ 844,1 mil de média por operação, em relação às demais modalidades. As doações de outros candidatos/comitês apresentaram média de R \$ 202,2 mil, as de pessoas físicas ficaram em R \$55,1 mil e as doações pela internet com média de apenas $\mathrm{R} \$ 222,3$. Embora tenha havido grande número de operações de doações pela internet, dado o valor médio das operações de pessoas jurídicas e partidos, a participação dessa modalidade para o financiamento da campanha nacional petista foi irrisória e poderia ser sido dispensada.

No caso do PSDB, embora os valores gerais tenham sido similares aos do PT, há grandes diferenças na distribuição das operações e dos valores por tipo de doador. No que diz respeito ao número de operações, $62 \%$ foram de pessoas jurídicas - mais que o dobro do PT - seguido de 16,7\% de outros candidatos/comitês e 12\% de partido político. Os valores arrecadados por tipo de doador também mudam bastante. No PSDB, ainda que as pessoas jurídicas somem o maior montante, representam $49,5 \%$ do total, cerca de metade do peso que esse tipo de doador teve na campanha nacional petista. Em segundo lugar, no PSDB, estão as doações de outros candidatos/comitês, com 36,5\%; seguido pelos partidos políticos, com $12,6 \%$ do total. Não houve registro de doação pela internet à campanha nacional do PSDB e os outros tipos de doadores tiveram participação irrisória. 0 valor médio por doação por tipo de doador também variou bastante em relação ao PT. No geral, as operações de doação à campanha nacional do PSDB apresentaram média de $\mathrm{R} \$ 780,8$ mil, praticamente três vezes acima da média do PT. A maior média do PSDB ficou com as transferências de outros candidatos/comitês, com R \$ 1,7 mi de média. Em segundo lugar veio partido político, com média de $\mathrm{R} \$$ 824 mil, e pessoas jurídicas, com média de $\mathrm{R} \$ 623,8$ mil. As pessoas 
físicas apresentaram média de $\mathrm{R} \$ 128,9$ mil por operação, conforme tabela 2 a seguir:

Tabela 2 - Doações para campanhas nacionais do PT e PSDB por tipo de doador

\begin{tabular}{|c|c|c|c|c|c|c|c|c|c|c|}
\hline \multirow{2}{*}{$\begin{array}{l}\text { Tipo de } \\
\text { Doador }\end{array}$} & \multicolumn{5}{|c|}{ PT } & \multicolumn{5}{|c|}{ PSDB } \\
\hline & $\mathbf{N}$ & $\%$ & Valor & $\%$ & Valor/N & $\mathbf{N}$ & $\%$ & Valor & $\%$ & Valor/N \\
\hline $\begin{array}{l}\text { Pessoas } \\
\text { Jurídicas }\end{array}$ & $\begin{array}{r}588 \\
(-5,8) \\
\end{array}$ & 30,7 & 495.032 .840 & 90,9 & $841.892,6$ & $\begin{array}{r}420 \\
(+9,7) \\
\end{array}$ & 62,0 & 261.999.866 & 49,5 & $623.809,2$ \\
\hline $\begin{array}{l}\text { Partido } \\
\text { Político }\end{array}$ & $\begin{array}{r}45 \\
(-5,0)\end{array}$ & 2,3 & 37.987 .035 & 7,0 & $844.156,3$ & $\begin{array}{r}81 \\
(+8,4) \\
\end{array}$ & 12,0 & 66.768 .830 & 12,6 & $824.306,5$ \\
\hline $\begin{array}{l}\text { Outros } \\
\text { cand./comitês }\end{array}$ & $\begin{array}{r}43 \\
(-6,7)\end{array}$ & 2,2 & 869.7962 & 1,6 & $202.278,2$ & $\begin{array}{r}113 \\
(+11,3)\end{array}$ & 16,7 & 192.441 .640 & 36,5 & $1.703 .023,4$ \\
\hline $\begin{array}{l}\text { Pessoas } \\
\text { Físicas }\end{array}$ & $\begin{array}{r}50 \\
(-3,3)\end{array}$ & 2,6 & 2.759 .050 & 0,4 & $55.181,0$ & $\begin{array}{r}57 \\
++5,5)\end{array}$ & 8,5 & 7349.418 & 1,4 & $128.937,2$ \\
\hline $\begin{array}{l}\text { Doações pela } \\
\text { Internet }\end{array}$ & $\begin{array}{r}1.192 \\
(+10,5) \\
\end{array}$ & 62,2 & 264.977 & 0,1 & 222,3 & $\begin{array}{r}0 \\
(-17,6) \\
\end{array}$ & & & & \\
\hline $\begin{array}{l}\text { Aplicações } \\
\text { financeiras }\end{array}$ & $\begin{array}{r}0 \\
(-1,9)\end{array}$ & & & & & $\begin{array}{r}5 \\
(+3,2) \\
\end{array}$ & 0,7 & 63.706 & 0,0 & $12.741,2$ \\
\hline $\begin{array}{l}\text { Origens não } \\
\text { identificadas }\end{array}$ & $\begin{array}{r}0 \\
(-0,9)\end{array}$ & & & & & $\begin{array}{r}1 \\
(+1,4)\end{array}$ & 0,1 & 200 & 0,0 & 200 \\
\hline Total & 1.918 & 100,0 & 544.741 .864 & 100,0 & $284.015,6$ & 677 & $\overline{100,0}$ & 528.623 .660 & 100,0 & $780.832,6$ \\
\hline
\end{tabular}

Coeficientes para $\mathrm{N}: \chi^{2}=874,72(\mathrm{p}=0,000)$

Fonte: autor, a partir de dados do TSE.

Em continuidade à descrição comparativa dos valores dos dois principais partidos, a Tabela 2 traz os coeficientes de resíduos padronizados (entre parênteses) para o número de operações de doação por tipo de doador e por partido. Os resíduos positivos mostram que tipo de operação predominou entre os dois partidos, independente das diferenças dos totais. Resíduos negativos mostram que, ao contrário, aquele tipo de doador esteve mais presente no outro partido. Os resíduos padronizados permitem comparar resultados absolutos, independente das diferenças de totais. No caso do PT, o único resíduo positivo está no número de operações pela internet $(+10,5)$, enquanto o PSDB apresenta resíduos positivos em todas as demais modalidades, com predomínio para doações de outros candidatos/partidos $(+11,3)$. Essas diferenças mostram que apesar dos efeitos dos altos valores doados por pessoas jurídicas e partidos, em número de operações o PT caracterizou-se por doadores via internet enquanto o PSDB recebeu mais doações de outros partidos/candidatos. Essas diferenças são confirmadas pelo coeficiente do teste de diferença de médias qui-quadrado (q2) que fica em 874,72, muito acima do limite crítico para rejeitar a hipótese nula de que não há diferenças 
estatisticamente significativas entre as participações dos tipos de doadores entre PT e PSDB.

Dos três tipos de entrada de recursos (ao candidato, via comitê financeiro da campanha ou pela doação ao diretório partidário), o primeiro gera uma relação direta entre candidato e doador, enquanto as outras duas não permitem identificação de imediato entre doador e candidato. São as chamadas formas indiretas de doação. A Tabela 3 mostra as frequências gerais de doações às campanhas nacionais por tipo de entrada. Em termos de número de operações houve um equilíbrio. 0 tipo de entrada que registrou maior número de operações foi comitê financeiro da campanha para presidente, com 39,8\%, seguida de doações ao diretório nacional do partido, com 31,3\% do total e doações aos candidatos, com $28,9 \%$.

Tabela 3 - Doações para campanhas nacionais por tipo de entrada em 2014

\begin{tabular}{l|c|c|c|c|c}
\hline Tipo entrada & $\mathbf{N}$ & $\mathbf{1}$ & \multicolumn{1}{c|}{ Valor } & \% & \multicolumn{1}{c|}{ Valor $/ \mathbf{N}$} \\
\hline Candidato & 2.400 & 28,9 & $641.505 .156,3$ & 35,1 & $267.293,8$ \\
\hline Comitê & 3.309 & 39,8 & $226.062 .361,8$ & 12,4 & $68.317,4$ \\
\hline Partido & 2.605 & 31,3 & $957.497 .880,1$ & 52,5 & $367.561,6$ \\
\hline Total & 8.314 & 100,0 & $1.825 .065 .398,2$ & 100,0 & $219.517,1$ \\
\hline
\end{tabular}

Fonte: autor, a partir de dados do TSE.

Note que as doações diretas aos candidatos representaram a menor parte do total de operações registradas para financiamento das campanhas. Em termos de valores, a maior entrada foi a dos partidos, com $52,5 \%$ do total de $\mathrm{R} \$ 1,8$ bi para as campanhas nacionais. Em seguida estão as doações diretas a candidatos, com $35,1 \%$ do total e, por fim, doações ao comitê financeiro, com $12,4 \%$ do total. Ou seja, os comitês receberam o maior número de operações, porém, o menor volume de recursos. 0 valor médio por operação reforça a informação anterior: as doações aos comitês apresentaram média de $\mathrm{R} \$ 68,3$ mil, contra $\mathrm{R} \$ 267,2$ mil por operação ao candidato e $\mathrm{R} \$ 367,5$ mil em média por doação ao partido. Os partidos receberam os maiores volumes de recursos, em grande medida porque aqui são considerados todos os 32 diretórios nacionais partidários, contra dez comitês financeiros e onze candidatos a presidente. Outra explicação é o fato de que muitas doações com valores altos, normalmente de pessoas jurídicas, são dirigidas aos partidos e não diretamente aos candidatos, para não vincular a imagem da empresa doadora à do candidato. 
Se compararmos os tipos de entrada dos dois principais partidos, há diferenças relevantes. No caso do PT, 79,6\% do total de 1.918 doações foram feitas diretamente à candidata a presidente, com 20,2\% das operações ao partido e apenas $0,3 \%$ ao comitê. Já no caso do PSDB foram $57,9 \%$ de doações ao partido, $24,2 \%$ ao comitê financeiro e apenas $17,9 \%$ diretamente ao candidato. Em relação aos valores recebidos, 64,4\% entraram na campanha do PT por doações à candidata e 35,5\% por meio de doações ao partido. Já para o PSDB, $42,2 \%$ das doações foram feitas diretamente ao candidato, seguido de $31,2 \%$ para o partido e $26,6 \%$ ao comitê. Os diretórios nacionais dos partidos PT e PSDB representaram praticamente o mesmo percentual de recursos das campanhas, em torno de $1 / 3$ dos valores. A diferença está nos outros dois tipos de entrada. Para o PT os outros 2/3 foram diretamente à candidata e praticamente nada pelo comitê financeiro. No PSDB o candidato representou menos da metade das entradas e o comitê fez pouco mais de $1 / 4$ dos recursos da campanha de Aécio Neves. 0 valor médio das doações ao partido ficou em R\$500,3 mil para o caso do PT e R\$ 421 mil para o PSDB. Nos outros dois tipos de entradas o valor médio do PSDB ficou bem acima do valor médio do PT. Para o candidato, o PSDB apresentou média de $\mathrm{R} \$ 1,8 \mathrm{mi}$ por doação, contra R\$229,6 mil para a candidata do PT. No caso do comitê financeiro da candidatura do PSDB a média ficou em $\mathrm{R} \$ 857,4$ mil por operação, contra R\$194,1 mil para o comitê financeiro do PT, o que pode ser percebido na Tabela 4.

Tabela 4 - Doações para campanhas nacionais do PT e PSDB por tipo de entrada

\begin{tabular}{l|r|c|c|c|c|r|c|c|c|c}
\hline \multirow{2}{*}{$\begin{array}{c}\text { Tipo de } \\
\text { Entrada }\end{array}$} & \multicolumn{5}{|c|}{ PT } & \multicolumn{5}{c}{ PSDB } \\
\hline & $\mathbf{N}$ & $\mathbf{\%}$ & Valor & $\mathbf{\%}$ & Valor/N & $\mathbf{N}$ & $\mathbf{\%}$ & Valor & \% & Valor/N \\
\hline Candidato & $\begin{array}{r}1.528 \\
(+8,9)\end{array}$ & 79,6 & $350.836 .282,00$ & 64,4 & $229.604,9$ & $\begin{array}{r}121 \\
(-14,9)\end{array}$ & 17,9 & $222.925 .813,00$ & 42,2 & $1.842 .362,1$ \\
\hline Comitê & $\begin{array}{r}4 \\
(-10,8)\end{array}$ & 0,3 & $776.737,00$ & 0,1 & $194.184,3$ & $\begin{array}{r}164 \\
(+18,2)\end{array}$ & 24,2 & $140.627 .273,00$ & 26,6 & $857.483,4$ \\
\hline Partido & $\begin{array}{r}386 \\
(-7,9)\end{array}$ & 20,2 & $193.128 .845,00$ & 35,5 & $500.333,8$ & $\begin{array}{r}392 \\
(+13,3)\end{array}$ & 57,9 & $165.070 .574,00$ & 31,2 & $421.098,4$ \\
\hline Total & 1.918 & 100,0 & $544.741 .864,00$ & 100,0 & $284.015,6$ & 677 & 100,0 & $528.623 .660,00$ & 100,0 & $780.832,6$ \\
\hline
\end{tabular}

Coeficientes para $\mathrm{N}: \chi^{2}=984,65(\mathrm{p}=0,000)$

Fonte: autor, a partir de dados do TSE.

Os testes de resíduos mostram que o tipo de entrada predominante no PT é diretamente ao candidato $(+8,9)$, enquanto o PSDB concentra operações nas outras duas modalidades, comitê 
financeiro $(+18,2)$ e diretório nacional do partido $(+13,3)$. Dadas essas diferenças, como esperado, o coeficiente do teste de diferença de média, qui-quadrado, para os dois partidos foi alto, em 984,65, ficando bastante acima do limite crítico. Isso reforça a ideia de que os dois partidos tiveram estratégias distintas para a recepção de doações. No PT houve predomínio de valores ao candidato, enquanto que no PSDB, embora o candidato tenha sido responsável pelo maior percentual das doações, ficou mais próximo do partido e do comitê financeiro.

Os gráficos 1.1 e 1.2 a seguir representam as diferenças proporcionais dos valores arrecadados pelos dois principais partidos na disputa presidencial de 2014. No Gráfico 1.1 estão reunidas todas as doações por tipo de entrada. As diferenças entre os totais de cada tipo de entrada são maiores no PT do que no PSDB. 0 comitê financeiro do PT recebeu apenas $R \$ 0,78 \mathrm{mi}$, contra $\mathrm{R} \$ 350,8$ milhões do próprio candidato, com o partido entre os dois polos, em R $\$ 193,1$ milhões. Já no PSDB as distâncias entre os polos são bem menores. 0 comitê recebeu $\mathrm{R} \$ 140,6 \mathrm{mi}$, o partido recebeu $\mathrm{R} \$ 165 \mathrm{mi}$ e o próprio candidato $\mathrm{R} \$ 222,9 \mathrm{mi}$. As informações do primeiro gráfico já constam na tabela anterior. As novas informações estão no gráfico 1.2, que separa os tipos de entrada por tipo de doador. Na imagem é possível identificar estratégias próprias de financiamento do PT e do PSDB.

Os recursos de outros candidatos/comitês, no caso do PT, são em valores baixos e apresentam poucas diferenças entre os tipos de entrada. No caso do PSDB esse tipo de doador faz transferências predominantemente para o candidato $\mathrm{R} \$ 174,8$ milhões. As doações de partido político para o PT vão exclusivamente para a candidata (R\$ 37,9 milhões), enquanto que no PSDB a maior parte, $\mathrm{R} \$ 45$ milhões, entra na campanha via comitê financeiro partidário. Os valores de pessoas físicas entram nas duas campanhas predominantemente via doação ao diretório nacional do partido. As diferenças principais ficam por conta das doações de pessoas jurídicas. No caso do PT a maior parte das doações de pessoas jurídicas vai diretamente à candidata ( $\mathrm{R} \$$ 305,5 milhões), seguida pelas doações ao partido (188,9 milhões) e um valor residual de $\mathrm{R} \$ 0,5$ milhão para o comitê financeiro. No PSDB a inversão é completa. 0 principal tipo de entrada de doações de pessoas jurídicas ao PSDB foi o diretório nacional do partido, com $\mathrm{R} \$ 141,9$ milhões. Em seguida vem o comitê financeiro da campanha, com $\mathrm{R} \$ 84$

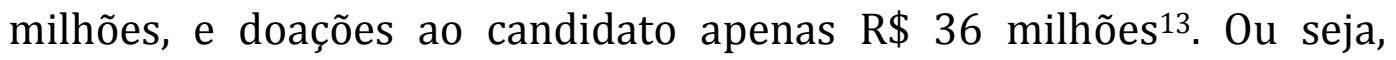

${ }^{13}$ Ainda que não seja objetivo deste artigo, vale ressaltar que estudos que busquem explicar a concentração de doações de empresas a partidos e não a candidatos de oposição fazem-se cada vez mais necessários. Há duas hipóteses aceitas correntemente que ainda dependem de testes para comprovação ou rejeição. A 
enquanto a maior parte das doações diretas ao candidato Aécio Neves foi de outros candidatos/comitês, no Caso de Dilma Rousseff, a maior parte das doações diretas à candidata foi de pessoas jurídicas.

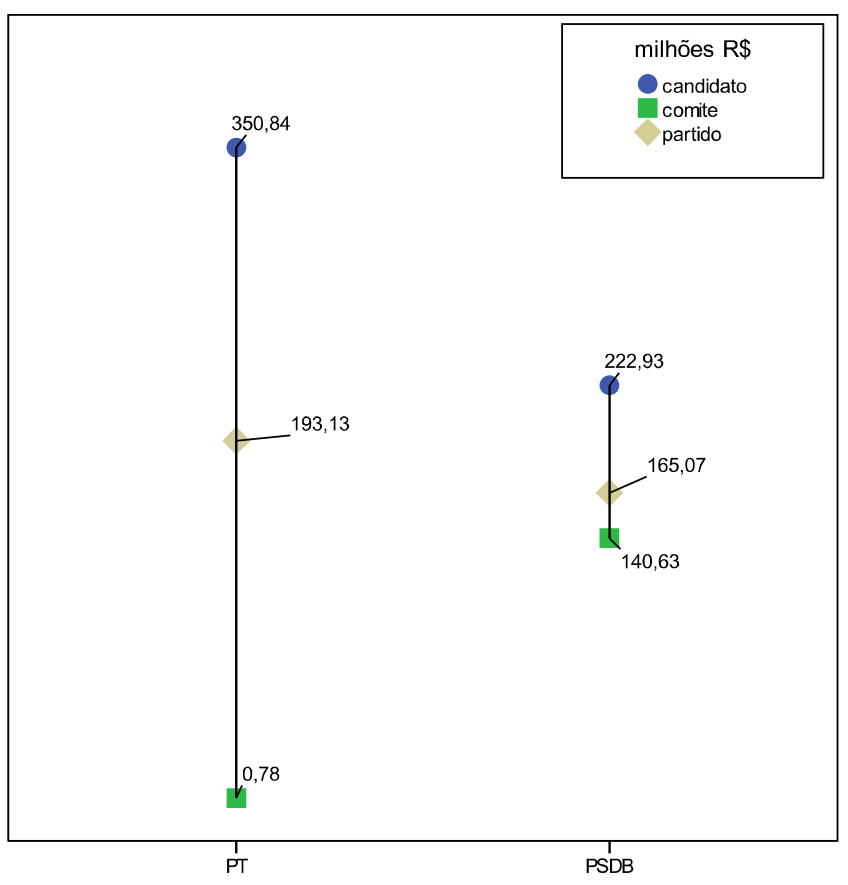

Gráfico 1.1. Total de recursos por tipo de entrada em milhões de $\mathbf{R}$ \$

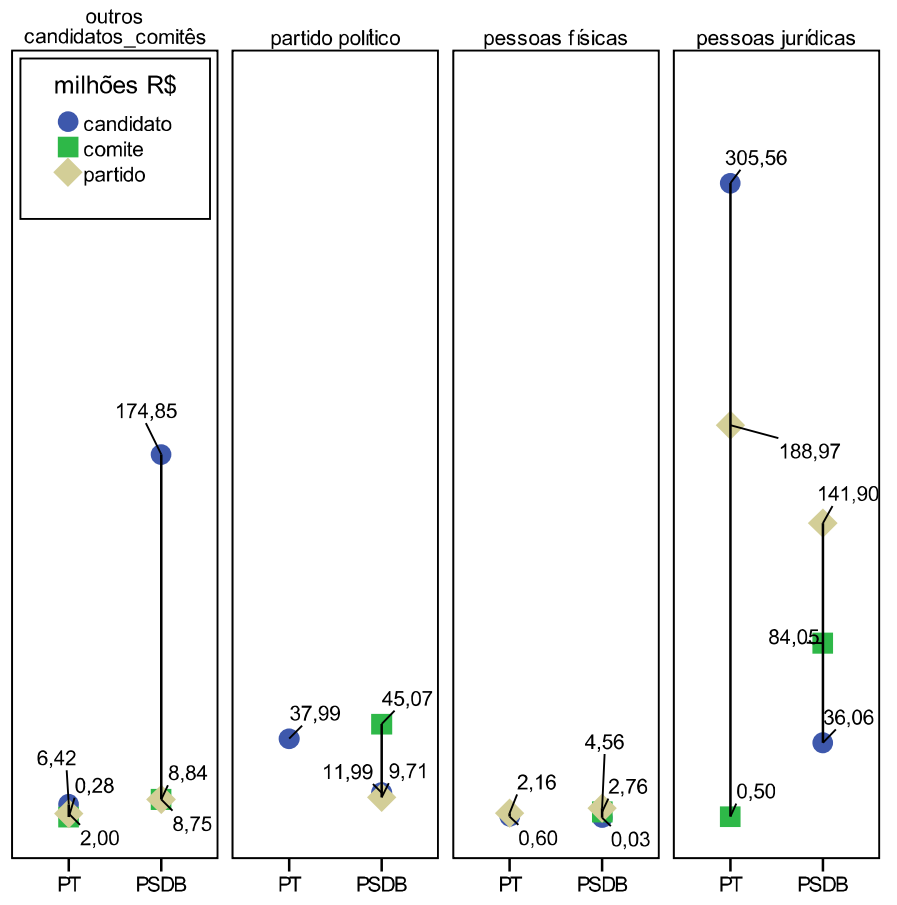

\section{Gráfico 1.2. Total de recursos por tipo de entrada e tipo de doador em milhões de R\$}

A Tabela 5 detalha as informações contidas no Gráfico 1.2. 0 principal tipo de entrada das pessoas jurídicas para a campanha do PT foi o candidato, com $61,7 \%$ do total, no PSDB a entrada principal foi por partido, com $54,2 \%$. No caso dos doadores partidos políticos, no PT todos os recursos entraram ao candidato. No PSDB, 67,5\% dos recursos recebidos de partidos políticos foram para o comitê financeiro de campanha. As doações de outros candidatos/comitês para o PT entraram diretamente ao candidato na proporção de $73,8 \%$ do total, enquanto que no PSDB 90,9\% das doações de outros candidatos/comitês foram para o próprio candidato. A distribuição das

primeira delas é que grandes empresas doam para candidatos de oposição porque não podem controlar ou antecipar os resultados da disputa. Assim, não doar a um candidato que pode ser eleito é um risco muito grande. Porém, ter a imagem da empresa vinculada diretamente a um candidato de oposição derrotado também pode ser negativo. A alternativa seria doar a opositores, porém, de maneira indireta, via partido político. Outra hipótese, menos institucional, é a de que as empresas doam para partidos por receito de ter suas marcas vinculadas às imagens pessoais dos candidatos. 
Doadores, partidos e estratégias para o financiamento de campanhas eleitorais no Brasil: uma análise sobre o reduzido número de doadores e os elevados valores doados para os candidatos a presidente em 2014 - Emerson Urizzi Cervi

doações de pessoas físicas também foi similar aos dois partidos. No PT, $78,1 \%$ foi para o partido e no PSDB $62 \%$ foi para o diretório nacional partidário. Apenas o PT declarou ter recebido doações via internet para a campanha presidencial e a totalidade foi diretamente ao candidato. Por outro lado, apenas PSDB declarou ter recebido recursos de aplicações financeiras, com 96\% entrando via partido político.

\section{Tabela 5. Operações e valores por doador e entrada em campanhas nacionais (2014)}

\begin{tabular}{|c|c|c|c|c|c|c|c|}
\hline \multirow{2}{*}{ Tipo de doador } & \multirow{2}{*}{$\begin{array}{ll}\text { Tipo } & \text { de } \\
\text { Entrada } & \end{array}$} & \multicolumn{3}{|c|}{ PT } & \multicolumn{3}{|c|}{ PSDB } \\
\hline & & $\mathbf{N}$ & Valor & $\%$ & $\mathbf{N}$ & Valor & $\%$ \\
\hline \multirow{4}{*}{ Pessoas jurídicas } & Candidato & 226 & 305.559 .331 & 61,7 & 15 & 36.056 .482 & $\overline{13,8}$ \\
\hline & Comitê & 1 & 500.000 & 0,1 & 102 & 84.045 .305 & 32,0 \\
\hline & Partido & 361 & 188.973 .509 & 38,2 & 303 & 141.898 .079 & 54,2 \\
\hline & Total & 588 & 495.032 .840 & 100,0 & 420 & 261.999 .866 & 100,0 \\
\hline \multirow{4}{*}{ Partido político } & Candidato & 45 & 37.987 .035 & 100,0 & 4 & 11.988 .762 & $\overline{18,0}$ \\
\hline & Comitê & 0 & & & 30 & 45.070 .000 & 67,5 \\
\hline & Partido & 0 & & & 47 & 9.710 .068 & 14,5 \\
\hline & Total & 45 & 37.987 .035 & 100,0 & 81 & 66.768 .830 & 100,0 \\
\hline \multirow{4}{*}{$\begin{array}{l}\text { Outros candidatos e } \\
\text { comitês }\end{array}$} & Candidato & 38 & 6.420 .899 & 73,8 & 98 & 174.851 .640 & 90,9 \\
\hline & Comitê & 3 & 276.737 & 3,2 & 6 & 8.750 .000 & 4,5 \\
\hline & Partido & 2 & 2000.326 & 23,0 & 9 & 8.840 .000 & 4,6 \\
\hline & Total & 43 & 8.697 .962 & 100,0 & 113 & 192.441 .640 & 100,0 \\
\hline \multirow{4}{*}{ Pessoas físicas } & Candidato & 27 & 604.040 & 21,9 & 3 & 26.400 & 0,4 \\
\hline & Comitê & 0 & & 0,0 & 26 & 2.761 .968 & 37,6 \\
\hline & Partido & 23 & 2.155 .010 & 78,1 & 28 & 4.561 .050 & 62,0 \\
\hline & Total & 50 & 2.759 .050 & 100,0 & 57 & 7.349 .418 & 100,0 \\
\hline \multirow{4}{*}{ Doações pela Internet } & Candidato & 1.192 & 264.977 & 100,0 & 0 & & \\
\hline & Comitê & 0 & & & 0 & & \\
\hline & Partido & 0 & & & 0 & & \\
\hline & Total & 1.192 & 264.977 & 100,0 & 0 & & \\
\hline \multirow{4}{*}{$\begin{array}{l}\text { Aplicações } \\
\text { financeiras }\end{array}$} & Candidato & 0 & & & 1 & 2.529 & 4,0 \\
\hline & Comitê & 0 & & & 0 & & \\
\hline & Partido & 0 & & & 4 & 61.177 & 96,0 \\
\hline & Total & 0 & & & 5 & 63.706 & 100,0 \\
\hline \multirow{4}{*}{$\begin{array}{l}\text { Origens não } \\
\text { identificadas }\end{array}$} & Candidato & 0 & & & 0 & & \\
\hline & Comitê & 0 & & & 0 & & \\
\hline & Partido & 0 & & & 1 & 200 & 100,0 \\
\hline & Total & 0 & & & 1 & 200 & 100,0 \\
\hline
\end{tabular}

Fonte: autor, a partir de dados do TSE. 
A associação entre tipo de doador e tipo de entrada ajuda a entender as diferenças nas estratégias dos dois principais partidos em relação às finanças da campanha nacional de 2014. Tanto no PT quanto no PSDB a maior parte das doações foi de "pessoas jurídicas". No caso do PSDB "outros candidatos/partidos" também teve peso importante. Do total de recursos recebidos de pessoas jurídicas, $61,7 \%$ foram diretamente à candidata do PT, enquanto o PSDB recebeu predominantemente doações de pessoas jurídicas via partido, com $54,2 \%$. Com isso a candidatura Aécio Neves fica menos vinculada diretamente às doações de empresas, embora esse tipo de doador tenha representado metade de todos os recursos da campanha nacional do PSDB. Um fato interessante é que apesar dos baixos valores, as doações de "pessoas físicas" são majoritariamente dirigidas ao partido e não ao candidato, com $78,1 \%$ no caso do PT e $62 \%$ no caso do PSDB, indicando que o eleitor comum tendeu a doar mais para o partido do que diretamente para a pessoa do candidato. Isso pode ser um indicativo de não querer vincular o nome do doador ao do candidato, como é a explicação mais aceita para as doações de pessoas jurídicas aos partidos, ou de forma alternativa pode ser entendida como sinal de partidarização da participação de eleitores como doadores de campanha.

Feitas as descrições dos tipos de doadores e tipos de entradas, analisam-se a partir daqui os efeitos conjuntos de três variáveis para buscar entender as relações entre tipo de doador, tipo de entrada e valor das doações. As duas primeiras são variáveis nominais e já foram descritas acima. 0 valor das doações individuais será inserido aqui para permitir identificar as associações não apenas entre diferentes tipos de doadores e entradas, mas também entre os grandes e pequenos doadores. Dada a grande variação de valores individuais, optou-se por trabalhar com a somatória do logaritmo das doações individuais por doador. Em primeiro lugar, os valores das 8,3 mil doações foram transformados em $\log _{10}$. Em seguida, foram agregados os $\log _{10}$ somando aqueles de doadores que fizeram mais de uma operação. Com isso, considera-se não apenas o peso do valor individual da doação, mas também o peso do número de doações. Por exemplo, se um doador fez uma única operação de $R \$ 1.000,00$, seu $\log _{10}$ será de 3 . Se outro doador doou $\mathrm{R} \$ 1.000,00$ para a campanha, porém, divididos em dez operações de $R \$ 100,00$, cada operação terá um $\log _{10}$ de 2 e, portanto, a somatória do $\log _{10}$ para esse doador será de 20 . A diferença está no fato de que o segundo doador participou mais do processo, embora com os mesmos valores do primeiro, mas com um número muito superior de operações. Em termos matemáticos, essa diferença acontece porque o $\log _{10}$ apresenta uma curva de crescimento exponencial e uma das 
características do logaritmo é que a somatória dos valores equivale à multiplicação dos mesmos [em termos matemáticos: $\log \mathrm{A}+\log \mathrm{B}=\log$ $(\mathrm{AxB})]$. A intensidade de operações financeiras de doação aqui é um fator de ponderação para a proximidade entre doador e campanha.

Usaremos a técnica de análise de dados categóricos indicada para a associação entre variáveis nominais e ordinais chamada Análise dos Componentes Principais (Catpca) ${ }^{14}$. Assim, o $\log _{10}$ que originalmente é uma variável contínua, será agregado em 7 categorias, indo do mais baixo ao mais alto, para ser computado no modelo. Na análise dos componentes principais as categorias de cada variável são comparadas conjuntamente e o resultado mostra quais são as ocorrências de categorias comuns entre si, considerando todos os casos. Quanto mais próximas estiverem as categorias de diferentes variáveis, mais elas se comportarão como integrantes de um mesmo conjunto, ou componente. As principais estatísticas geradas pelo teste são o $\alpha$ de Cronbach, que indica quanto o modelo está explicando das variações. Há também indicadores de variância explicada em todo o modelo. No caso das variáveis individuais, o teste fornece os coeficientes de "carregamento" para duas dimensões. Quanto mais próximos estiverem os coeficientes entre duas variáveis, mais as categorias delas estão covariando na mesma direção. Por fim, o teste gera um gráfico que distribui as categorias de cada variável em eixos próprios. As direções dos eixos das variáveis indicam a presença de variações no mesmo sentido. Os gráficos apresentam o ponto centróide das duas dimensões e a partir dele é possível identificar os quadrantes da distribuição. Aqui, categorias de variáveis dentro do mesmo quadrante formam um componente.

Mantendo a sequência de apresentação anterior, considerando todos os partidos na campanha nacional a Tabela 6 mostra um coeficiente $\alpha$ de Cronbach de 98,2\% de explicação do modelo, com variação explicada de $96,56 \%$, o que mostra que o modelo é altamente explicativo. Já em relação às variações das categorias, percebe-se que na dimensão 2 as categorias que mais se associam são as do $\log$ do valor da doação e o tipo de doação, com coeficientes de -0,299 e -0,196 respectivamente. O PT apresenta coeficientes muito próximos dos obtidos com todos os partidos. O Cronbach é praticamente o mesmo, em $98,9 \%$, e as duas variáveis mais próximas estão na dimensão 2 , com $\log$ do valor da doação e tipo de doador. Para o PSDB os resultados variam um pouco. A explicação cai para um Cronbach de $94 \%$ e

\footnotetext{
14 Para maiores informações sobre a técnica de análise em diferentes áreas de pesquisa ver Fleck e Bourdel (1998); Moreira (2007); Martinez e Sepúlveda (2012) e Fernando (2014).
} 
variância explicada de 89,36\%. Mas a maior diferença está no carregamento das variáveis para o modelo, onde as variáveis mais próximas são tipo de doador e tipo de entrada, na dimensão 1 , com coeficientes de 1,049 e 1,060 .

Tabela 6 - Principais resultados da Análise de Componentes Principais

\begin{tabular}{|c|c|c|c|c|c|c|}
\hline Estatísticas CATPCA & \multicolumn{2}{|c|}{ TODOS } & \multicolumn{2}{|c|}{ PT } & \multicolumn{2}{|c|}{ PSDB } \\
\hline Cronbach total & \multicolumn{2}{|c|}{0,982} & \multicolumn{2}{|c|}{0,989} & \multicolumn{2}{|c|}{0,940} \\
\hline Variância explicada total & \multicolumn{2}{|c|}{2,897} & \multicolumn{2}{|c|}{2,935} & \multicolumn{2}{|c|}{2,681} \\
\hline \% variância explicada total & \multicolumn{2}{|c|}{$96,56 \%$} & \multicolumn{2}{|c|}{$97,83 \%$} & \multicolumn{2}{|c|}{$89,36 \%$} \\
\hline № interações & \multicolumn{2}{|c|}{100} & \multicolumn{2}{|c|}{31} & \multicolumn{2}{|c|}{23} \\
\hline Carregamento & D1 & D2 & D1 & D2 & D1 & D2 \\
\hline Log valor doação & 0,930 & $-0,299$ & 0,998 & $-0,375$ & $-0,143$ & 1,302 \\
\hline Tipo doador & 0,952 & $-0,196$ & 0,993 & $-0,408$ & 1,049 & 0,197 \\
\hline Tipo entrada & 0,828 & 0,560 & 0,882 & 0,884 & 1,060 & $-0,020$ \\
\hline
\end{tabular}

Os gráficos 2.1 a 2.3 distribuem as categorias por quadrantes de componentes. No caso de todos os partidos, os eixos de log do valor e tipo de doador apresentam distribuições muito próximas, conforme indicado nos coeficientes de carregamentos da tabela acima. No Gráfico 2.1, o eixo das categorias de tipo de entrada é o que se encontra em outra distinta. Além disso, as categorias de log de valor mais altas, 6 e 7, as categorias de doadores pessoas jurídica e recursos próprios estão no mesmo quadrante, indicando uma tendência de maiores valores desses dois tipos de doadores. Todas as demais categorias de doadores ficam no quadrante com os log mais baixos.

0 Gráfico 2.2, com informações apenas de doadores do PT, mostra um comportamento muito parecido com o total, com pessoas jurídicas, pessoas físicas e partido político formando um componente com os valores mais altos de log de doação. 0 outro componente é formado por valores baixos de doações e doações pela internet. 0 tipo de entrada apresenta eixo em outra direção, mostrando pouca similaridade de variação com as categorias das outras variáveis. As mais altas categorias de log de valor de doações coincidem com o tipo de doador "pessoas jurídicas", seguido por "pessoas físicas" e partido político. 0 Gráfico 2.3 mostra que a principal diferença do PSDB em relação aos componentes principais anteriores está na distribuição das 
Doadores, partidos e estratégias para o financiamento de campanhas eleitorais no Brasil: uma análise sobre o reduzido número de doadores e os elevados valores doados para os candidatos a presidente em 2014 - Emerson Urizzi Cervi

categorias de log do valor da doação. 0 eixo dessa variável está deslocado do das outras duas. As categorias de doações de pessoas jurídicas, pessoas físicas, os tipos de entrada partido e comitê ficam muito próximos da categoria 5 do log do valor, indicando que no caso do PSDB há concentração de valores intermediários, nem muito altos, nem muito baixos, nesses tipos de doadores e tipos de entrada.

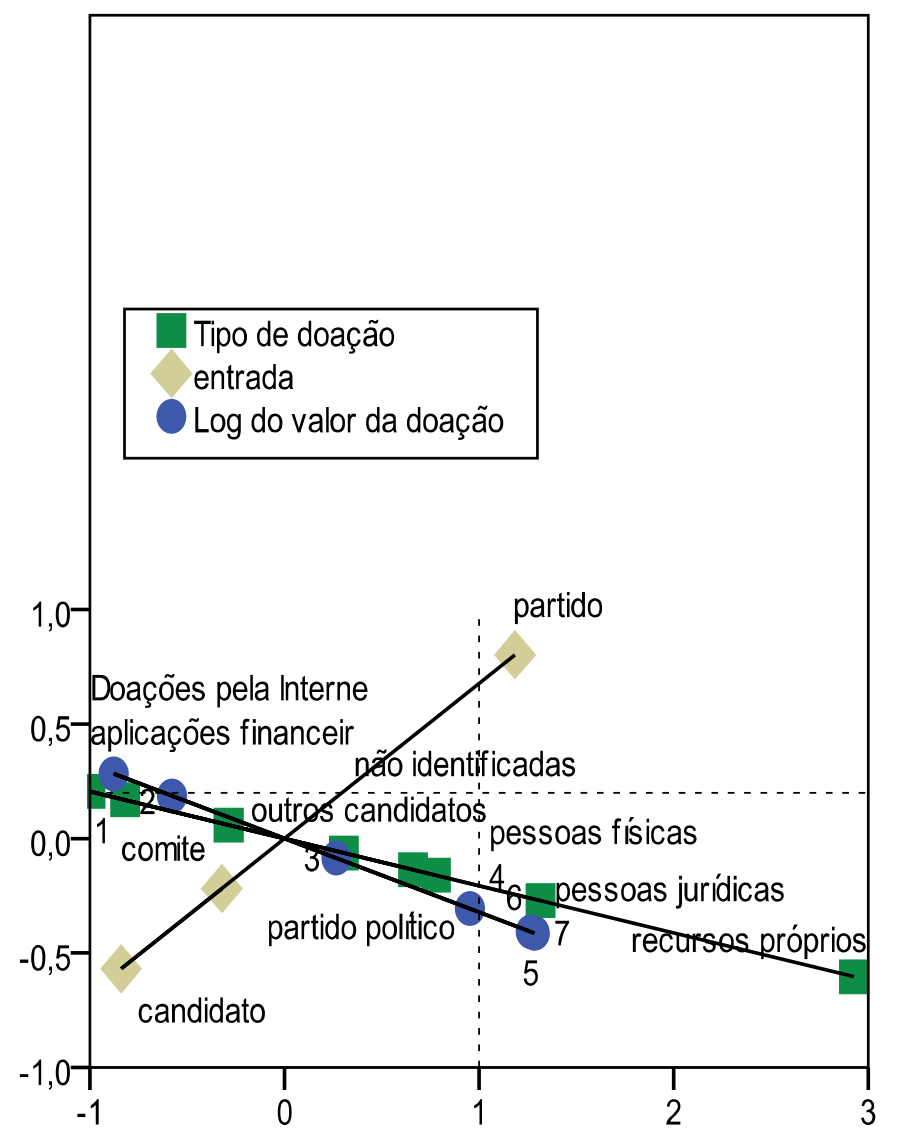

Gráfico 2.1 Componentes principais de todos os partidos 


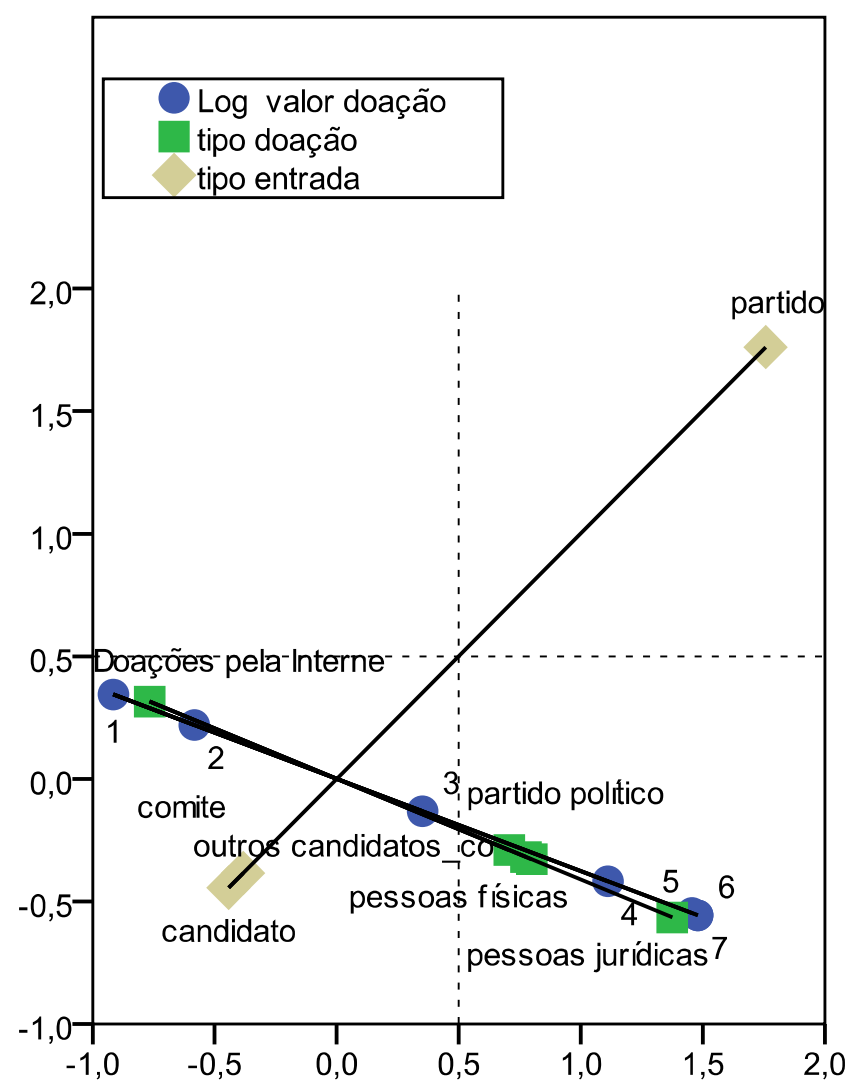

\section{Gráfico 2.2 Componentes principais do PT}

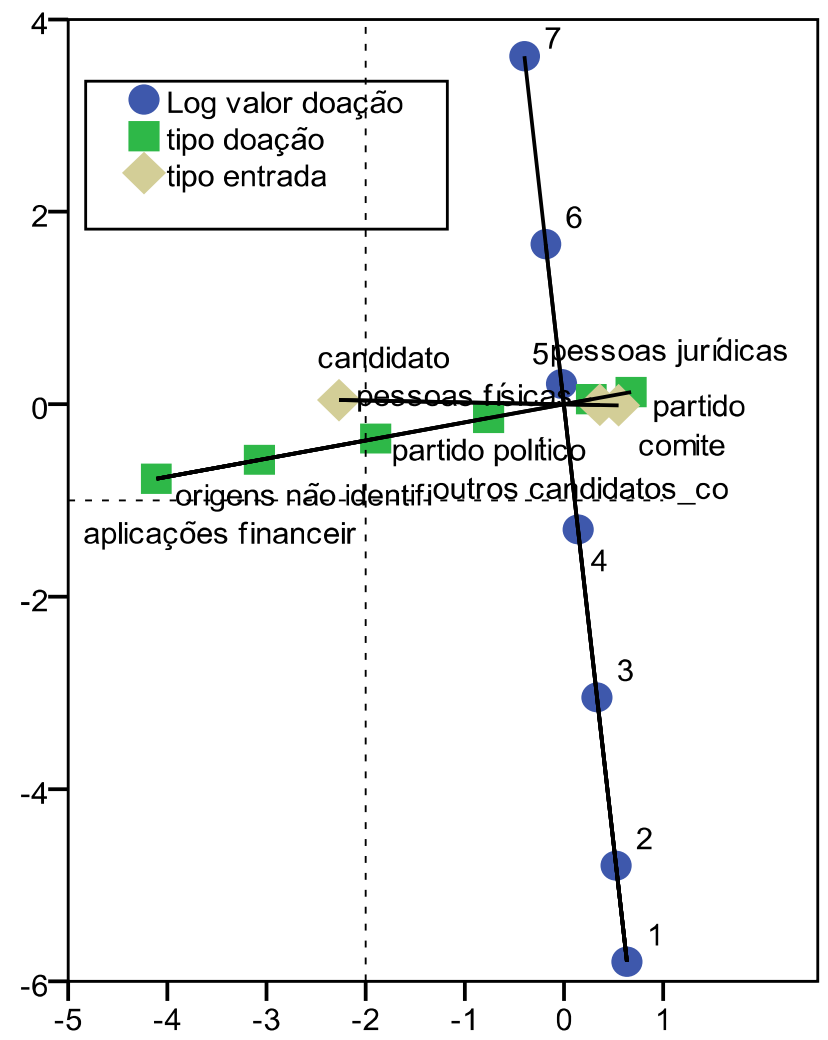

\section{Gráfico 2.3 Componentes principais do PSDB}


0 teste de componentes principais reforça os achados anteriores, a partir das variáveis isoladas. Em primeiro lugar, há um padrão de doações quanto ao tipo e valor das doações, exceto para o caso do PSDB. Doações pela internet, de outros candidatos e pessoas físicas tendem a ser de baixo valor e os valores vão aumentando conforme o tipo de doador passa a ser pessoa jurídica ou recursos próprios. No caso do PSDB não há um padrão de variação. Isso porque boa parte das doações fica distante dos extremos, são na maioria das vezes de pessoas jurídicas destinadas ao diretório nacional do partido.

Até aqui as diferenças entre os padrões de doações às campanhas nacionais foram consideradas consequências de estratégias dos partidos/coordenações de campanhas. Isso poderia explicar o peso maior das doações ao partido e comitê do PSDB e o predomínio das doações diretas à candidata do PT, em especial quando o doador é pessoa jurídica. Porém, devemos ter em mente que doadores também são agentes racionais que, diante das opções disponíveis, podem fazer doações para diferentes partidos e tipos de entrada em função de seus próprios interesses. No próximo tópico são analisadas as estratégias de doação dos principais financiadores das campanhas nacionais de 2014 por partido e por tipo de entrada dos recursos nas campanhas.

\subsection{Quem foram os maiores doadores para as campanhas nacionais em 2014?}

Nosso recorte dos principais doadores levou em conta apenas os doadores de grandes valores declarados pelas campanhas nas prestações de contas ao TSE. Para definir o número, utilizamos como corte o ponto de $99,9 \%$ de doadores, ou seja, consideramos apenas os $0,1 \%$ dos maiores doadores. Isso resultou em uma lista com cinco nomes - todos pessoas jurídicas, como era de se esperar. Juntos, esses cinco doadores transferiram para as campanhas nacionais (considerando doações a diretórios partidários nacionais, candidatos e comitês financeiros) mais de $\mathrm{R} \$ 648$ milhões, o que representa 36\% do total de $\mathrm{R} \$ 1,8$ bi declarados. Em outras palavras, dos 5,9 mil doadores, os cinco maiores, apenas $0,1 \%$, foram capazes de fornecer $36 \%$ de todos os recursos usados nas campanhas nacionais. Para se ter ideia da desproporção do peso dessas empresas no financiamento eleitoral de 2014, o valor médio da doação nesse grupo fica próximo de $R \$ 2$ milhões. A média de todas as doações ficou em $\mathrm{R} \$ 219,1 \mathrm{mil}$, dez vezes menos. Já a mediana dos valores, que divide o total de 8,3 mil doações em duas partes iguais, foi de apenas $\mathrm{R} \$ 175,00$. Ou seja, metade das 
operações para as campanhas nacionais ficou abaixo desse valor, mais de dez mil vezes abaixo da média dos grandes doadores.

A Tabela 7 sumariza as informações dos cinco maiores doadores das campanhas nacionais de 2014. Na primeira coluna ("doador") consta o nome da empresa doadora e o número de operações que ela realizou durante toda a campanha $(\mathrm{N})$. Os valores doados tiveram destino identificado para o PT, para o PSDB e o conjunto de todos os demais partidos. As colunas seguintes indicam os valores doados pela empresa para o partido por tipo de entrada: se diretamente ao candidato, se ao comitê financeiro de campanha ou se ao diretório nacional do partido. Os percentuais referem-se ao total doado para os três grupos de partidos (PT, PSDB e outros) e às três modalidades de entrada (candidato, comitê e partido). A coluna seguinte mostra os totais doados pela empresa a cada partido, junto com o percentual relativo ao total. A última coluna traz o valor total doado pela empresa à campanha nacional de 2014. A última linha da tabela mostra os totais e percentuais doados pelos cinco maiores doadores por tipo de entrada. Ela permite identificar que o tipo de entrada predominante para as doações dos grandes doadores foi o partido político, com $58,4 \%$ do total; depois vem o diretamente ao candidato, com 31,5\%, e por último as doações aos comitês financeiros representaram apenas 10,1\% do total em 2014. 
Doadores, partidos e estratégias para o financiamento de campanhas eleitorais no Brasil: uma análise sobre o reduzido número de doadores e os elevados valores doados para os candidatos a presidente em 2014 - Emerson Urizzi Cervi

Tabela 7 - Formas de doações dos principais doadores da campanha nacional (2014)

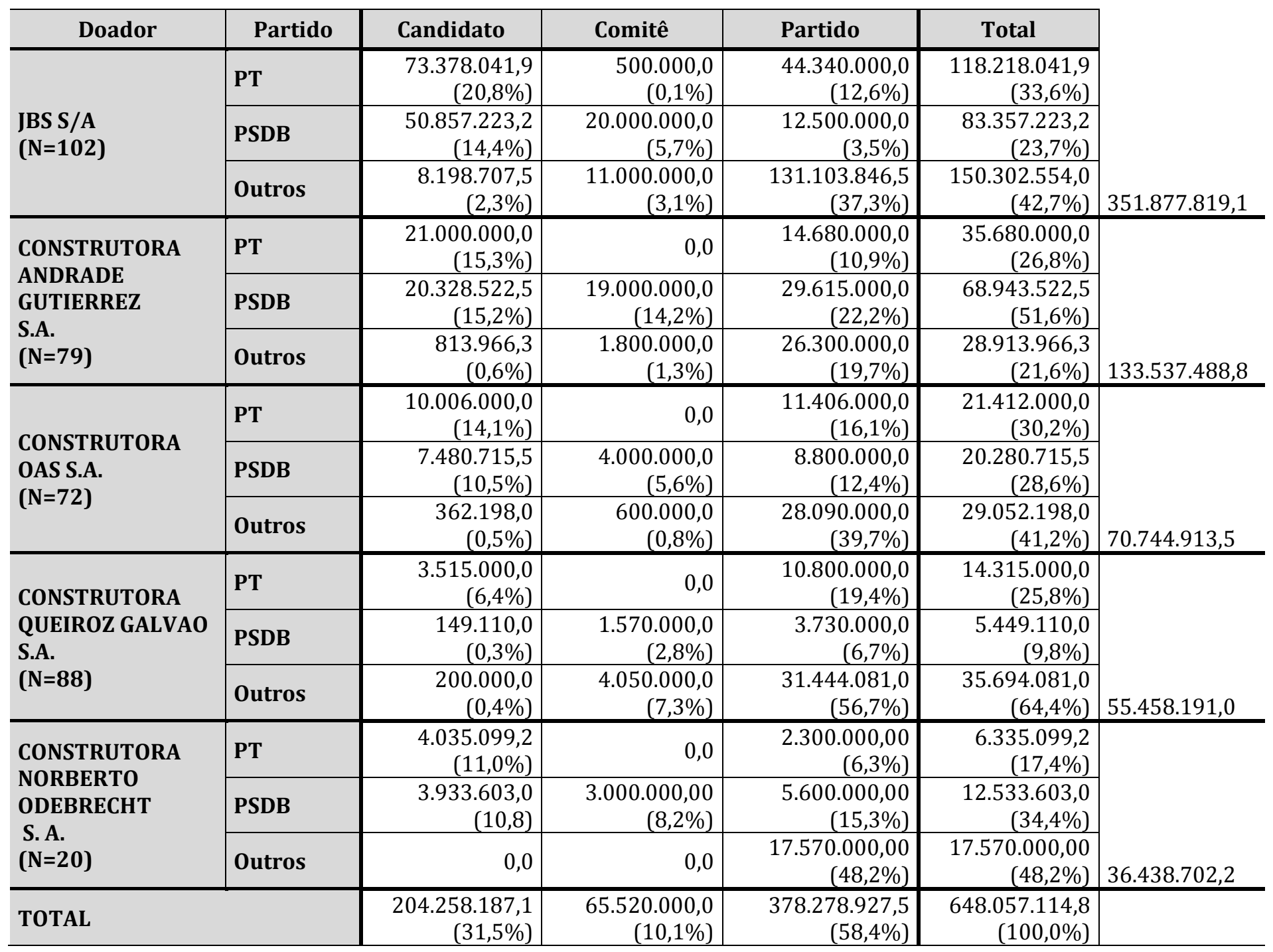

Fonte: autor, a partir de dados do TSE.

Entre os cinco maiores doadores aparece uma exportadora de alimentos, a JBS S/A, e quatro empreiteiras: Construtora Andrade Gutierrez, OAS, Queiroz Galvão e Odebrecht. Quando olhamos a distribuição das doações deles aos partidos percebemos que quatro deles fizeram a maior parte de suas doações a outros partidos que não PT e PSDB. Apenas a Construtora Andrade Gutierrez S.A. doou a maior parte de suas contribuições de campanha, 51,6\%, para o PSDB. O PT não recebeu a maior fatia de recursos de nenhum dos cinco principais doadores de 2014, conforme detalhado a seguir.

A JBS S/A foi a maior doadora individual, contribuindo com $\mathrm{R} \$$ $351,8 \mathrm{mi}$ às campanhas nacionais. Ela também apresentou o maior número de operações de doações, em um total de 102 operações nos 
quatro meses de campanha. Do total do valor, $42,7 \%$ foi para outros partidos, seguido de $33,6 \%$ para o PT e $23,7 \%$ para o PSDB. Considerando os tipos de entradas, a JBS doou principalmente para partidos, sendo que os diretórios de outros partidos que não PT e PSDB representaram a maior fatia, 37,3\%. Em segundo lugar vieram as doações diretas à candidata Dilma Rousseff, com 20,8\%, seguida de doações a Aécio Neves, 14,4\%, e doações ao diretório nacional do PT, $12,6 \%$. As demais categorias apresentaram valores pouco significativos.

Em segundo lugar em total de doações, $R \$ 133,5 \mathrm{mi}$, e em número de operações, 79 doações, vem a Construtora Andrade Gutierrez S.A. Essa construtora privilegiou a campanha nacional do PSDB em suas doações, totalizando 51,6\% dos recursos destinados ao partido. Em seguida vem o PT, com $26,8 \%$, e os outros partidos, com $21,6 \%$ do total. Quanto às formas de entradas, a Andrade Gutierrez S.A. destinou mais da metade dos valores de suas doações aos diretórios nacionais partidários. Apenas o diretório do PSDB ficou com 22,2\% das doações dessa empreiteira. A segunda principal forma de entrada foi a de doações a outros partidos, com 19,7\% do total. Depois estão as doações à candidata Dilma Rousseff, com 15,3\%, seguida de perto pelas doações a Aécio Neves, 15,2\%. Doações ao comitê financeiro do PSDB representaram 14,2\% do total e ao diretório nacional do PT outros 10,9\%. As demais modalidades ou não foram usadas ou os valores são muito baixos. Como se vê, a Andrade Gutierrez dividiu os valores destinados aos candidatos do PT e PSDB em partes praticamente iguais, mas dobrou o valor destinado ao partido PSDB em comparação com o PT. Por isso o predomínio do PSDB nos valores doados pela empreiteira.

0 terceiro maior doador individual foi a Construtora OAS S.A., com 72 operações realizadas durante a campanha, totalizando $R \$ 70,7$ milhões para as candidaturas nacionais de 2014. 0 padrão de doações da OAS ficou muito próximo do identificado no primeiro caso. 0 maior volume de recursos foi destinado a outros partidos, $41,2 \%$, seguido pelas doações ao PT, 30,2\%, e pelo PSDB, com 28,6\% do total. Em termos de tipos de entradas, a OAS destinou a maior parte dos recursos para diretórios de outros partidos, 39,7\% do total, seguido de doações ao diretório nacional do $\mathrm{PT}$, com 16,1\%; à candidata a presidente do PT, $14,1 \%$ e ao candidato a presidente do PSDB, 10,5\%. Todas as demais modalidades tiveram participações baixas, conforme tabela anterior.

O quarto doador em total de valores, com $\mathrm{R} \$ 55,4 \mathrm{mi}$ foi a Construtora Queiroz Galvão, embora ela tenha feito mais operações que 
as duas anteriores, chegando a 88 doações durante a campanha. A Queiroz Galvão preferiu doar a outros partidos, 64,4\%, e não aos dois maiores. O PT ficou com $25,8 \%$ e o PSDB com apenas $9,8 \%$ do total de recursos declarados da empreiteira. 0 principal tipo de entrada para ela foi por via diretórios nacionais de outros partidos políticos, representando $56,7 \%$ do total. Em seguida vem o diretório nacional do PT, com $19,4 \%$ do total e todos os demais tipos de entrada ficam abaixo de $10 \%$ do total doado.

A Construtora Norberto Odebrecht S.A. foi a quinta maior doadora individual para as campanhas nacionais em 2014, com $R \$ 36,4$ mi, distribuídos em 20 operações. Ela também optou em destinar mais recursos ao outros partidos, com 48,2\% do total. A diferença é que do restante o PSDB ficou com a maior parte, $34,4 \%$, e o PT com apenas $17,4 \%$ do total. Entre as modalidades de entrada, os diretórios nacionais de outros partidos representaram 48,2\%, pois essa foi a única forma de doação da empresa para outros partidos. A empresa Norberto Odebrecht não doou diretamente a nenhum outro candidato ou comitê que não aos dois principais. 0 diretório nacional do PSDB ficou com $15,3 \%$ do total doado, seguido pela candidata Dilma Rousseff, do PT, com 11\% e de Aécio Neves, com 10,8\%.

Excetuando a Construtora Queiroz Galvão, que doa muito mais à candidata do PT que do PSDB, os demais grandes doadores tendem fazer doações com valores similares diretamente aos candidatos dos principais partidos. Essas doações são bem superiores às feitas a outros partidos. E, mais importante, os valores destinados aos dois principais candidatos variam entre $20 \%$ e $40 \%$ do total doado pelas empresas que fizeram os maiores volumes de doações de campanha.

\section{Conclusões}

Em processos eleitorais de democracias representativas de massa existem diferentes indicadores intermediários da relação entre representantes e representados, quase todos levando ao indicador principal que é o voto. Recursos financeiros são necessários para manter as máquinas partidárias funcionando e para financiar as campanhas eleitorais. A fonte desses recursos tem se tornado um dos indicadores mais importantes, depois do voto, de representação das ligações entre os partidos políticos e os segmentos sociais que eles pretendem representar. Quanto mais recursos ou de quanto mais doadores provém o dinheiro dos partidos, maior a capacidade de representação política dele na sociedade. No entanto, assim como os sistemas de representação, a regulação da forma de financiamento da 
política não é perfeita. Mesmo quando se propõe a oferecer as condições mais democráticas de participação através de doações, a legislação pode gerar sistemas altamente restritivos na prática. Foi o que aconteceu com o financiamento das campanhas nacionais de 2014 no Brasil. Foi uma campanha com muitos recursos doados por poucos financiadores e a grande parte do eleitorado completamente ausente do sistema de financiamento de campanhas. Esses ingredientes levam a uma concentração de poder de alguns agentes econômicos na relação com os agentes políticos, em detrimento da proximidade entre partidos e segmentos da sociedade. A impressão que se tem ao final de uma campanha com o padrão de financiamento descrito aqui é de um quase completo afastamento entre representantes políticos e representados sociais.

A legislação brasileira é altamente permissiva quanto aos possíveis doadores. Todos os quase 150 milhões de eleitores podem fazer doações. Se somarmos a esses outros 17 milhões de pessoas jurídicas que atendem a legislação eleitoral, temos um universo potencial superior a 160 milhões de doadores de campanha. No entanto, em 2014 para as campanhas nacionais apenas 5,9 mil realizaram operações de doação, um número irrisório perto do potencial de doadores. Isso mostra que na prática o que deveria ser um modelo de relação entre representante e representado aberto das doações financeiras em uma democracia de massa se transformou em um sistema altamente seletivo e restritivo. Com a finalidade de ganho de escala, os partidos deixam de procurar os pequenos doadores, filiados ou não, para manter contato direto com as grandes empresas, capazes de em uma só operação equivaler a milhares de doações de pessoas físicas. Os valores médios das doações confirmam essas diferenças. Enquanto o valor médio por doação de partido político fica em $\mathrm{R} \$ 779,5$ mil e de pessoas jurídicas $\mathrm{R} \$ 602$ mil, as operações de pessoas físicas apresentam valor médio de $\mathrm{R} \$ 41,6$ mil e as doações por internet - forma mais segura de doação para a prestação de contas ficou em $\mathrm{R} \$ 147,3$. Essa distorção impede qualquer possibilidade de considerar que o eleitor mediano é capaz de contribuir de fato com seu partido fazendo doações nos valores próximos à sua realidade. Sempre as grandes empresas conseguirão doar mais e, com isso, chamar a atenção dos partidos para suas demandas. Valer ressaltar que esses valores só puderam ser encontrados em função da opção inicial do trabalho em considerar não apenas as doações aos candidatos, mas também aos comitês de campanha para presidente e aos diretórios nacionais dos partidos.

Quando consideramos apenas os dois maiores partidos na disputa percebem-se algumas similaridades no geral e diferenças em 
aspectos específicos da arrecadação de recursos. A primeira semelhança está no valor total que PT e PSDB conseguiram arrecadar para suas campanhas nacionais: $\mathrm{R} \$ 544,7 \mathrm{mi}$ e $\mathrm{R} \$ 528,6 \mathrm{mi}$, respectivamente. Juntos eles representaram quase $60 \%$ de todos os valores declarados para as candidaturas nacionais em 2014. Ou seja, os partidos grandes, com chances reais de chegar ao segundo turno, concentram a maior parte das doações de poucos grandes doadores. Isso é outro fator de desequilíbrio das condições de disputa. As diferenças começam nos tipos de doadores a cada um dos partidos. Enquanto quase a totalidade das doações à campanha nacional do PT foi de pessoas jurídicas, 90,9\%, no PSDB as pessoas jurídicas representaram 49,5\%, mantendo-se como o principal tipo de doador ao partido. No entanto, dos $\mathrm{R} \$ 66,7 \mathrm{mi}$ doados por partido político à campanha do PSDB uma parte considerável não é proveniente do fundo partidário e sim de doações de empresas ou pessoas físicas, colocando o PSDB em patamares próximos ao do PT em termos de percentual de participação das pessoas jurídicas no financiamento de sua campanha nacional. 0 que significa que enquanto grandes doadores fizeram doações diretamente à candidata do partido incumbent, praticamente os mesmos doadores preferiram contribuir para a campanha do principal candidato adversário de forma indireta - via doações partidárias.

Se os poucos doadores que importam nas campanhas nacionais têm suas próprias estratégias para doar, elas podem ser identificadas no tipo de entrada dos recursos nas campanhas. Muitas vezes um grande doador não quer ter sua "marca" vinculada diretamente ao nome de um candidato. Outras vezes, uma mesma empresa faz doações para vários candidatos. Em todos os casos, existem alternativas para financiar campanhas nacionais que não seja via doação direta ao candidato. Nas campanhas nacionais de 2014 apenas $35,1 \%$ dos $\mathrm{R} \$ 1,8$ bi foi doada diretamente aos candidatos a presidente. A forma de entrada que contou com o maior volume de doações foram os diretórios nacionais dos partidos, que receberam 52,5\% do total. Por fim vieram os comitês de campanha para presidente, com 12,4\%. Qualquer análise sobre o financiamento de campanha presidencial em 2014 que desconsidere as fontes "partido" e "comitê" subestimará os valores que entraram nas campanhas. Além do mais, as distribuições dos percentuais variam entre os partidos. Apenas considerando as duas candidaturas que chegaram ao segundo turno, as diferenças são evidentes. No caso do PT houve predomínio de entrada de recursos diretamente ao candidato, com $64,4 \%$ do total, seguido das doações ao partido, com 35,5\%. As doações ao comitê nacional de campanha foram insignificantes, representando apenas $0,1 \%$ do total. Para o PSDB, 
menos da metade dos recursos foram doados diretamente ao candidato, $42,2 \%$. Outra parte significativa, $31,2 \%$, entrou via partido para a campanha nacional e 26,6\% foram via comitê de campanha para presidente. Considerando que a maior parte das doações foi feita por um número reduzido de empresas e que essas tenderam a doar para vários partidos, fica evidente que houve uma tendência de vínculo direto entre doador e candidata do PT enquanto que no caso do PSDB a opção pelo vínculo indireto, via comitê ou partido, foi predominante.

0 teste de Componentes Principais realizado neste trabalho confirma o "achado" de que os doadores do PSDB tiveram um comportamento distinto do PT e dos demais partidos. 0 teste indica que variáveis e categorias apresentam as maiores similaridades quando consideradas todas as variações em conjunto. No caso de todos os candidatos, o teste de componentes principais formou um componente com eixos muito próximos do valor da doação e tipo de doação. Valores menores tenderam a se posicionar junto a doações pela internet e de outros candidatos. Os valores médios ficaram próximos a doações de pessoas físicas enquanto os maiores valores se aproximaram das doações de pessoas jurídicas. Já o tipo de entrada distribui-se em outro eixo, fora da dimensão das duas anteriores. Para o PT os componentes principais ficaram muito próximos da distribuição de todos os partidos, com o eixo dos valores coincidindo com o eixo dos tipos de doação. Menores valores com doações pela internet. Valores intermediários com doações de partido político e pessoas físicas. Por fim, os maiores valores coincidem com doações de pessoas jurídicas. Quando são considerados apenas os doadores do PSDB há outra formação. Os eixos que mais se aproximam são do tipo de doador e tipo de entrada, com valores distribuídos em direções opostas. Isso indica que a variação de valores doados não se associa a tipo de entrada ou de doador. Em especial os valores muito baixos ou muito altos, que ficam nas extremidades do eixo, distante das categorias das outras variáveis. Aqui, a informação mais importante é que a categoria de doador "pessoa jurídica" está coincidindo com as categorias de tipo de entrada "partido" e "comitê", indicando que empresas doaram pouco diretamente ao candidato do PSDB. Elas preferiram fazer doações indiretas, via partido ou comitê financeiro, embora em termos absolutos os valores gerais do PSDB tenham ficado próximos dos do PT. O candidato tucano recebeu doações principalmente do próprio "partido político", que foi quem repassou os recursos de outras fontes para a campanha.

Por fim, a análise dos maiores doadores comprovou a concentração de recursos em poucos agentes políticos. Apenas os cinco maiores doadores (que representa $0,01 \%$ do total registrado em 2014) 
foram responsáveis por cerca de $1 / 3$ dos recursos que entraram nas campanhas nacionais de todos os partidos em 2014. Nenhum deles fez doação a apenas um partido ou candidato. Eles distribuíram parte de seus recursos entre diferentes campanhas e em distintas formas de entrada. No geral, apenas $10,1 \%$ dos recursos desses grandes doadores foram para comitês financeiros de campanha. Outros 31,5\% foram diretamente para candidatos, enquanto a maior parte, 58,4\%, para os diretórios nacionais dos partidos políticos. Em média, cerca de metade dos valores doados pelas cinco empresas descritas no trabalho destinaram-se a candidatos ou partidos que não o PT e o PSDB. Esses dois partidos representaram entre $10 \%$ e $50 \%$ dos recursos destinados pelos principais doadores às campanhas nacionais.

Os resultados apresentados aqui para o estudo de caso das disputas nacionais de 2014 permitem afirmar que não há, na prática, embora esteja formalmente constituído, um sistema democrático de financiamento de campanhas nacionais no Brasil. Isso ocorre porque o desequilíbrio gerado por um pequeno número de doadores neutraliza qualquer interesse dos partidos em pequenos doadores, tendo como consequência a concentração de poucos grandes doadores de campanha. Os efeitos dessa proximidade entre candidatos/partidos e grandes doadores são controversos na literatura e não se pretendeu tratar deles aqui. 0 que esperamos ter demonstrado é que o doador individual, identificado como eleitor médio, não participa do financiamento político no Brasil, embora as campanhas estejam cada vez mais caras e o volume de recursos para financiá-las mais caudaloso.

\section{Referências}

ALMEIDA, Noely Manfredini d'. Financiamento de partidos e campanhas no mundo. Curitiba: TRE-PR. Paraná Eleitoral, n. 39, p. 31-38, jan./mar. 2001.

BIEZEN, Ingrid V. \& KOPECKY, Peter. 2007. The state and the parties: public funding, public regulation and rent-seeking in contemporary democracies. Los Angeles. Party Politics Review, v. 13, n. 2, p. 235-254.

BOURDOUKAN, Adla Y. 2008. Financiamento político em perspectiva comparada. Trabalho apresentado no 6 o Encontro da Associação Brasileira de Ciência Política ABCP. Campinas, 2008.

BRAGA, Maria do Socorro Sousa. BOURDOUKAN, Adla. Partidos políticos no Brasil: organização partidária, competição eleitoral e financiamento público. Perspectivas, São Paulo, v. 35, jan./jun. 2009. p. 117-148.

CERVI, Emerson U. Financiamento de Campanha e desempenho eleitoral no Brasil: análise das contribuições de pessoas jurídicas, físicas e partidos 
políticos às eleições de 2008 nas capitais de Estado. Revista Brasileira de Ciência Política, no 4, p. 135-167, julho-dezembro 2010.

FERNANDO, Avelina M. M. Palhares. Análise Fatorial para Variáveis Ordinais. Dissertação de mestrado: Faculdade de Economia. Universidade do Porto, 2014. Disponível em:

http://repositorio-aberto.up.pt/bitstream/10216/77405/2/105488.pdf

FISCHER, Justin \& EISENSTADT, Todd A. Introduction: comparative party finance. What is to be done? Party Politics Review, v. 10, n. 6, 2004, p. 619626.

FIGUEIREDO FILHO, Dalson Britto. 0 elo corporativo? Grupos de interesse, financiamento de campanha e regulação eleitoral, Tese de Mestrado, UFPE, Recife, 2009.

FLECK, Marcelo P. A. \& BOURDEL, Marie C. Método de simulação e escolha de fatores na análise dos principais componentes. Revista de Saúde Pública/ Journal of Public Health. Vol. 32. № 3, 1998 (p. 266 a 272).

FLEISCHER, David. As eleições municipais no Brasil: uma análise comparativa (1982-2000). Opinião Pública, v 8, n 1, Campinas, 2002.

GUARNIERI, F. Comportamento eleitoral e estratégia partidária nas eleições presidenciais no Brasil (2002 - 2010). Opinião Pública, v. 20, n. 2, p. 157$177,2014$.

HEILER, Jeison Giovanni. Democracia: Jogo das incertezas $x$ Financiamento de campanhas. Uma análise das prestações de contas das campanhas de vereadores de SC, Tese de Mestrado, UFSC, Florianópolis, 2011.

HOPKIN, Jonathan. 2004. The problem with party finance: theoretical perspectives on the funding of party politics.Los Angeles. Party politics, v. 10 , n. 6, p. 627-651.

JONES, Ruth. 1981. State public campaign Finance: Implications for Partisan Politics.American Journal of Political Science, New York. v. 25, n. 2, p. 342361.

KATZ, Richard S. \& MAIR, Peter. 1995. Changing models of party organization and party democracy: the emergence of the cartel party. Los Angeles. Party Politics, v. 1, n. 1, p. 5-28.

LIMA, Sídia Maria P. O controle Jurídico da movimentação de recursos nas campanhas eleitorais: Uma preocupação mundial. Revista do Tribunal Regional Eleitoral de Pernambuco, Recife, PE, v. 5, n. 1, 2004. p. 29-46.

MANN, Thomas. El sistema de financiamiento de campañas em Estados Unidos bajo estúdio: problemas y perspectivas de cambio.Revista Ciência Politica. Chile. Vol. 20. № 1, 1999 (p. 61 a 84).

MARENCO DOS SANTOS, A. Não se fazem mais oligarquias como antigamente: recrutamento parlamentar, experiência política e vínculos partidários entre deputados brasileiros (1946-1998). Porto Alegre - RS: Universidade Federal do Rio Grande do Sul - UFRGS, 2000. 
Doadores, partidos e estratégias para o financiamento de campanhas eleitorais no Brasil: uma análise sobre o reduzido número de doadores e os elevados valores doados para os candidatos a presidente em 2014 - Emerson Urizzi Cervi

MARTÍNEZ, Carolina M. \& SEPÚLVEDA, Martín Alonso R. Introducción al Análisis Factorial Exploratorio. Revista Colombiana de Psiquiatria. vol. 41. № 2, 2012 (p. 197 a 207).

MOREIRA, António Carrizo. Comparação da Análise de Componentes Principais e da CATPCA na avaliação de satisfação do passageiro de uma transportadora aérea. Revista Investigação Operacional. nํㅜ 27, 2007 (p. 165 a 178).

PEIXOTO, Vitor de Moraes. 2005. Modelos de financiamento de campanhas e accountability: uma análise comparativa e um teste de hipótese. Trabalho apresentado no XXIX Encontro anual da Anpocs. Caxambu-MG. 23 a 25 de outubro.

PINTO-DUSCHINSKY, Michael. Financing politics: a global view. Journal of Democracy, Baltimore. v. 13, n. 4, 2002.

RODRIGUES, L. M. Mudanças na classe política brasileira.São Paulo: PubliFolha, 2006.

ROSEN, Ruth S. State public campaign finance: implications for partisan politics. American Journal of Political Science, New York. v. 25, n. 2, 1981, p. 342-360.

RUBIO, Delia Ferreira. Financiamento de Partidos e Campanhas: Fundos públicos versus fundos privados. Novos Estudos Cebrap, São Paulo. n. 73, 2005.

SÁEZ, Manuel Alcántara. Sistemas políticas de América Latina. Madrid: Editorial Tecnos, 2013 (4⿳亠丷a edição).

SAMUELS, David. Money, elections, and democracy in Brazil. Latin American Politics and Society, Vol. 43, No. 2, p.27-48, 2001a.

SAMUELS, David.Does money matter? Credible commitments and campaign finance in new democracies: theory and evidence from Brazil.Comparative Politics, Vol. 34, No. 1, pp. 23-42, 2001b.

SAMUELS, David.When does every penny count? Intra-party competition and campaign finance in Brazil. Party politics, Vol. 7, no. 1, p. 89-102, 2001c.

SAMUELS, David.Pork barreling is not credit claiming or advertising: campaign finance and the source of the personal vote in Brazil.The Journal of Politics, Vol. 64, no. 3, p. 845-863, 2002.

SANTOS, Rodrigo D. Grandes empresários e sucesso eleitoral nas eleições de 2002, 2006 e 2010. Paper apresentado no 35으 Encontro Anual da Anpocs, Caxambu-MG, 2011.

SCARROW, Susan E. Explaining political finance reforms: competition and context.Party Politics Review, Los Angeles. v. 10, n. 6, 2004, p. 653-675.

SILVEIRA, Bernardo S. da, MELLO, João Manoel Pinho de. Campaign Advertising and Election Outcomes: Quasi-Natural Experiment Evidence from Gubernatorial Elections in Brazil. Textos para Discussão no. 550, Departamento de Economia, PUC Rio de Janeiro, 2011. 
SPECK, Bruno W. Reagir a escândalos ou perseguir ideais? A regulação do financiamento político no Brasil. Cadernos Adenauer, Ano 6, no. 2, p. 123159, 2005.

SPECK, Bruno W. \& MANCUSO, Wagner P. O financiamento político nas eleições brasileiras de 2010: um panorama geral. Paper apresentado no 35을 Encontro Anual da Anpocs, Caxambu-MG, 2011.

TAAGEPERA, Rein e SHUGART, M.S. Shugart. Seats \& Votes: The effects $\&$ determinats of Electoral Systems. New Haven: Yale University Press, 1989.

ZOVATTO, Daniel. 2005. Financiamento dos partidos e campanhas eleitorais na América Latina: uma análise comparada. Opinião Pública, Campinas. v. XI, n. 2, 2005. p. 287-315.

Recebido em 11 de novembro de 2015

Aprovado em 27 de janeiro de 2016

\title{
Parties, donors and strategies for the electoral campaigns financing in Brazil: An analysis of the limited number of donors and the high donations for the president's candidates in 2014
}

\begin{abstract}
The paper write in the campaign finance research to discuss the importance of the origin and form of donation to national electoral campaign in Brazil, 2014. The goal is to analyze how the donations are made and how they are declared in presidencies campaigns. To better understand the specific decisions, the PT and PSDB campaign finances are compared with the other parties in the dispute of 2014. Among the main findings are the fact that direct donations to candidates accounted for only $1 / 3$ of the total $\mathrm{R} \$ 1,8$ bi declared. Despite highly open, in practice the campaign financing system is "closed" to a small group of large companies who contributed considerable sums in presidential campaigns. Less than $0.01 \%$ of donors accounted for over $20 \%$ resources declared by national campaigns.
\end{abstract}

Keywords: Elections, financing, president, Brazil, 2014. 